\title{
Thermodynamic Modelling and Microstructural Study of Z-Phase Formation in a Ta-Alloyed Martensitic Steel
}

\author{
Florian Riedlsperger ${ }^{1, *(\mathbb{D})}$, Bernadette Gsellmann ${ }^{1}$, Erwin Povoden-Karadeniz ${ }^{2,3}{ }^{(\mathbb{D}}$, Oriana Tassa ${ }^{4}$, \\ Susanna Matera ${ }^{4}$, Mária Dománková ${ }^{5}$, Florian Kauffmann ${ }^{6}$, Ernst Kozeschnik ${ }^{3}{ }^{\mathbb{D}}$ and Bernhard Sonderegger ${ }^{6,7}$ \\ 1 Institute of Materials Science, Joining and Forming (IMAT), Graz University of Technology, \\ 8010 Graz, Austria; bernadette.gsellmann@gmx.at \\ 2 Christian-Doppler Laboratory for Interfaces and Precipitation Engineering CDL-IPE, TU Wien, \\ 1060 Wien, Austria; erwin.povoden-karadeniz@tuwien.ac.at \\ 3 Institute of Materials Science and Technology, TU Wien, 1060 Wien, Austria; ernst.kozeschnik@tuwien.ac.at \\ 4 CSM Centro Sviluppo Materiali, 00128 Rome, Italy; oriana.tassa@rina.org (O.T.); \\ susanna.matera@rina.org (S.M.) \\ 5 Institute of Materials Science of MTF STU, 91724 Trnava, Slovakia; maria.domankova@stuba.sk \\ 6 Materials Testing Institute (MPA), University of Stuttgart, 70569 Stuttgart, Germany; \\ florian.kauffmann@mpa.uni-stuttgart.de (F.K.); bernhard.sonderegger@jku.at (B.S.) \\ 7 Institut für Metallische Konstruktionswerkstoffe, JKU Linz, 4040 Linz, Austria \\ * Correspondence: florian.riedlsperger@tugraz.at; Tel.: +43-316-873-1674
}

Citation: Riedlsperger, F.;

Gsellmann, B.;

Povoden-Karadeniz, E.; Tassa, O.;

Matera, S.; Dománková, M.;

Kauffmann, F.; Kozeschnik, E.;

Sonderegger, B. Thermodynamic

Modelling and Microstructural Study of Z-Phase Formation in a Ta-Alloyed Martensitic Steel. Materials 2021, 14, 1332. https://doi.org/10.3390/ ma14061332

Academic Editor: Jiri Svoboda

Received: 12 February 2021

Accepted: 8 March 2021

Published: 10 March 2021

Publisher's Note: MDPI stays neutral with regard to jurisdictional claims in published maps and institutional affiliations.

Copyright: (c) 2021 by the authors. Licensee MDPI, Basel, Switzerland. This article is an open access article distributed under the terms and conditions of the Creative Commons Attribution (CC BY) license (https:/ / creativecommons.org/licenses/by/ $4.0 /)$.

\begin{abstract}
A thermokinetic computational framework for precipitate transformation simulations in Ta-containing martensitic Z-steels was developed, including Calphad thermodynamics, diffusion mobility data from the literature, and a kinetic parameter setup that considered precipitation sites, interfacial energies and dislocation density evolution. The thermodynamics of Ta-containing subsystems were assessed by atomic solubility data and enthalpies from the literature as well as from the experimental dissolution temperature of Ta-based Z-phase CrTaN obtained from differential scanning calorimetry. Accompanied by a comprehensive transmission electron microscopy analysis of the microstructure, thermokinetic precipitation simulations with a wide-ranging and well-documented set of input parameters were carried out in MatCalc for one sample alloy. A special focus was placed on modelling the transformation of MX into the Z-phase, which was driven by Cr diffusion. The simulation results showed excellent agreement with experimental data in regard to size, number density and chemical composition of the precipitates, showing the usability of the developed thermokinetic simulation framework.
\end{abstract}

Keywords: thermodynamics; precipitate kinetics; microstructure; modelling; steel; creep

\section{Introduction}

Martensitic 9-12\% Cr steels are widely used high-temperature alloys with excellent stability against corrosion, outstanding creep resistance [1] and low manufacturing costs [2] compared to austenitic steels or nickel base alloys. They are reasonably tough, can resist frequent thermal loads [3] and combine good thermal conductivity with low thermal expansion [4]. The main fields of application for steel grades such as E911, P91 and P92 today are in turbine parts or surroundings, pipes and boilers or heat exchangers in thermal power plants [5]. In order to reduce the $\mathrm{CO}_{2}$ emissions of fossil-fired power plants, their thermal efficiency must be further maximized by increasing the operational temperature and pressure [6]. In fact, elevated temperature environments pose a challenge in terms of creep resistance. Steels with $9-12 \%$ Cr owe their high creep strength to a fine substructure that is embedded in martensitic packets and blocks inside of prior austenitic grains and to numerous precipitates located at grain and subgrain boundaries [7]. Apart from the chromium-carbide $\mathrm{M}_{23} \mathrm{C}_{6}, \mathrm{MX}$ carbonitrides in particular provide significant precipitate strengthening [8] due to their small size and high number density. These 
precipitates both impede mobile dislocation movement and are assumed to pin subgrain boundaries [8-10]. Traditionally, finely distributed MX carbonitrides, typically in the size range of 20 to $40 \mathrm{~nm}$ [11,12], have been introduced by the addition of $\mathrm{V}$ and $\mathrm{Nb}$ (e.g., in P91 and P92). However, the optimized precipitate distribution degrades within the scope of MX transformation into thermodynamically more favourable, coarse modified Z-phase in the order of hundreds of nm [13] by Cr in-diffusion [14]. MX transformation into modified Z-phase is made responsible for a breakdown in creep life and premature failure [15].

Two strategies have been proposed to avoid these issues: (i) Formation of Z-phase can be slowed down and its detrimental effect may be delayed as long as possible-ideally beyond the planned service life of power plant components-by alloying adjustment (e.g., avoiding high Cr contents, such as in P122) [6]. (ii) Development of Z-steels: a new promising alternative is to replace $\mathrm{V}$ and $\mathrm{Nb}$ in $\mathrm{MX}$ carbonitrides by Ta [16] in 11-12\% $\mathrm{Cr}$ steels. Ta $(C, N)$ transforms very quickly into small and evenly distributed CrTaN Z-phase particles already during heat treatments in the manufacturing process [17]. Strikingly, this Ta-based Z-phase turned out to have high stability against coarsening during creep [18,19].

For modified Z-phase of the type $\mathrm{Cr}(\mathrm{V}, \mathrm{Nb}) \mathrm{N}$, four formation mechanisms are proposed [20]: (i.) already existing face-centred cubic (fcc) MX carbonitride precursors serve as nucleation sites, or (ii.) MX transforms into Z-phase, supported by Cr-consumption from the matrix [20]; it has also been observed that (iii.) hexagonal closed packed (hcp) $\mathrm{M}_{2} \mathrm{X}$ precursors (of the composition $\mathrm{Cr}_{2} \mathrm{~N}$ ) may act as spots of Z-phase nucleation [21], respectively, and (iv.) may transform into $\mathrm{Z}$-phase due to $\mathrm{V} / \mathrm{Nb}$ intake.

Similar processes take place in Z-steels: Cr entering into MX or Ta diffusing into $\mathrm{M}_{2} \mathrm{X}$ have been shown as (trans)formation mechanisms for Ta-based Z-phase [22].

From a crystallographic point of view, fcc MX or hcp $\mathrm{M}_{2} \mathrm{X}$ precursors are replaced by cubic and later tetragonal Z-phase $[14,23]$ to minimize the Gibbs energy and reach thermodynamic stability. The authors of [23] interpret the cubic structure as a metastable, transient Z-phase stage, whereas those of [16] propose the co-existence of cubic and tetragonal structures.

For technical usability of Z-steels, MX precursors are generally preferred, since they result in small Z-phases, whereas the $\mathrm{M}_{2} \mathrm{X}$ mechanism may produce undesired oversized Z-phases [22]. Three factors control the question of which precursor type predominates: (i.) heat-treatment [21,22] (particularly the tempering conditions), (ii.) C content [22] (the higher, the more $\mathrm{MX}$ ) and (iii.) $\mathrm{Ta} / \mathrm{N}$ ratio (the more excess $\mathrm{N}$, the more $\mathrm{M}_{2} \mathrm{X}$ ) [22].

A special characteristic of Ta-based Z-phase is its stoichiometry of $\mathrm{Cr}_{1+\mathrm{x}} \mathrm{Ta}_{1-\mathrm{x}} \mathrm{N}$ with $x=0.2$ in final stage [24]. To determine the degree of transformation, often the $\mathrm{Cr}: \mathrm{Ta}$ ratio is stated [25]. For a fully evolved Ta-based Z-phase with completed element intake, $\mathrm{Cr}: \mathrm{Ta}=1.5$ [25]. In contrast, so-called MX/Z-hybrid particles define an intermediate stage with $\mathrm{Cr}: \mathrm{Ta}=0.5$, indicating that the transformation has started or is currently ongoing [26]. In-depth microstructural analysis revealed that they may contain zones of both MX and Z-phase [14].

In this work, we present the first study of Calphad thermodynamics-based predictions of precipitate evolution in a Ta-containing Z-steel. Results of the thermokinetic precipitation simulation with MatCalc [27] are validated by transmission electron microscopy (TEM) results and atom probe tomography (APT) data from the literature [18]. A thermodynamic description of Ta-based Z-phase was ascertained by differential scanning calorimetry (DSC) and implemented in the open-source steel database "mc_fe" [28].

\section{Materials and Methods}

Two 10-12\% Cr-steels, denoted as ZULC (ultra-low carbon) and Z6, were investigated. ZULC was one of the first trial steels to investigate the characteristics of Ta-based Z-phase; the results have been well documented $[18,19,25]$. ZULC in this work served to detect the dissolution temperature of the Z-phase. Z6 ranks amongst the latest candidates for industrial application of this material group and has been recently developed within the 
EU project CRESTA2 (RFSR-CT-2014-00032). For Z6, a detailed microstructural and phase analysis was conducted in this work along with equilibrium and thermokinetic simulations.

Chemical compositions of ZULC and Z6 are shown in Table 1. The main differences of these concern $\mathrm{C}$ content (higher in Z6) and $\mathrm{Cr}$ (more in ZULC). The Ta and $\mathrm{N}$ contents are very similar. The chemical composition of Z6 was measured in this work by optical emission spectrometry (OEM), except for Ta content, which had been previously determined by X-ray fluorescence spectroscopy (XRF) [29]. Please note that the C-content of Z6 from OEM (0.017 wt.\%) significantly differed from the value documented in [29] (only 0.009 wt.\%) which was obtained by combustion analysis of the melt. Chemistry of ZULC was adopted from the literature $[18,19,25]$.

Table 1. Chemical composition of materials in wt.\%.

\begin{tabular}{cccccccc}
\hline wt. $\%$ & Fe & Ni & Cu & Cr & W & Mo & Si \\
\hline ZULC & bal & 0.50 & - & 11.79 & 2.90 & - & 0.30 \\
\hline Z6 & bal & 0.22 & 0.98 & 10.90 & 1.70 & 0.74 & 0.05 \\
\hline wt. \% & Mn & $\mathbf{C}$ & $\mathbf{N}$ & $\mathbf{C o}$ & Ta & B & V \\
\hline ZULC & 0.48 & 0.005 & 0.033 & 7.30 & 0.39 & 0.004 & - \\
\hline Z6 & 0.49 & $\begin{array}{c}0.009- \\
0.017\end{array}$ & 0.035 & 3.71 & 0.38 & 0.003 & 0.013 \\
\hline
\end{tabular}

Simulation. Thermodynamic equilibrium and precipitate kinetic simulations were run by MatCalc version 6.03 (rel. 1.003) on a Windows 10 system with 64 bits and 4 Intel Core 2 Quad Q9550 @ 2.83 GHz processors. The used databases were "mc_fe_v2.061.tdb" (for thermodynamics) and "mc_fe_v2.013.ddb" (for diffusion data). Only equilibrium was calculated for ZULC. Equilibrium and precipitate kinetics-consisting of the stages of normalizing, tempering and ageing-were simulated for Z6.

Microstructural investigations and phase characterization. Basic microstructural and phase information such as grain and subgrain sizes, but also sites of preferred precipitate nucleation, represent important inputs for the thermokinetic simulation setup. On the other hand, experimental observations allow plausibility checks of the simulation results and provide a deepened insight into precipitate characteristics, i.e., particle sizes, number densities and compositions.

The TEM analysis findings were employed for Z6. A FEG JEOL 3200FS operated at $300 \mathrm{kV}$ from CSM (Centro Sviluppo Materiali) was used for the TEM precipitate analysis. Carbon extraction replicas were prepared as follows: Samples were polished and Vilella etched at $20{ }^{\circ} \mathrm{C}$ (without electrochemical device). Samples were then cleaned before evaporating carbon on them. Finally, the replicas were stripped with a geometry of $2 \times 2 \mathrm{~mm}^{2}$, etched again (making stripped areas peel off) and applied to a TEM copper grid. Beam conditions in selected area diffraction (SAD) were chosen for generating dark and bright field diffraction contrast images. Precipitate phases were identified by crystallographic analysis with SAD and by energy-dispersive X-ray spectroscopy (EDX).

The TEM measurement of dislocations and subgrains in Z6 was performed at MTF STU (Slovak University of Technology). For this purpose, thin foils were prepared. Discs with a diameter of $3 \mathrm{~mm}$ and a thickness of $100 \mu \mathrm{m}$ were jet-electropolished in electrolyte $\mathrm{HNO}_{3}: \mathrm{CH}_{3} \mathrm{OH}=3: 7$ at $0{ }^{\circ} \mathrm{C}$ and $15 \mathrm{~V}$ to obtain transparent areas near the central hole. Bright-field images were produced from a microscope JEOL 200CX operating at $200 \mathrm{kV}$. A mean linear intercept method was used to quantify observed dislocations in subgrain interiors (in the following referred to as $\rho_{\text {int }}$ ): An array of horizontal and vertical lines was introduced to the TEM images and intersection points were counted. The number of intersections was then weighted according to line length and sample thickness to obtain dislocation densities. For further details on the method, see, e.g., [12].

The chemistry of Z6 was confirmed by OES at MPA Stuttgart, applying 4 sparks to a $21 \times 21 \times 10 \mathrm{~mm}^{3}$ sample in condition 0 (before the start of normalizing). 
An overview of all investigated Z6 sample conditions is given in Section 5.

The dissolution temperature of Ta-based Z-phase was determined by DSC at TU Wien on a normalized ZULC sample provided by Chalmers University of Technology. Tests were run on a high-temperature DSC machine 404C Pegasus (manufactured by the company Netzsch in Selb, Germany) at $20 \mathrm{~K} / \mathrm{min}$ heating and cooling.

\section{Incorporation of Ta into Thermodynamic and Diffusion Mobility Databases}

For simulations of the transformation from MX to Z-phase in Ta-alloyed Cr-steel, multicomponent thermodynamic and diffusion mobilities in "mc-fe" databases (openlicense databases "mc_fe_v2.060.tdb" and "mc_fe_v2.012.ddb" [28]) were extended by thermodynamic information on Ta. Key parameters in this regard are the solubilities of Ta in MX, $\mathrm{M}_{2} \mathrm{X}$, and Z-phase. Associated solubility limits of Ta in austenitic and ferritic alloy phases play an essential role as well. Interaction energies between $\mathrm{Fe}$ and $\mathrm{Ta}$, and $\mathrm{Cr}$ and $\mathrm{Ta}$ in ferrite and austenite were taken from the thermodynamic Calphad description of binary Fe-Ta [30] and Cr-Ta [31], respectively. In "mc_fe_v2.060", TaC and TaN compound energies were added to the description of fcc-type MX carbonitrides, based on available Ta-C, Ta-N Calphad descriptions and considerations of Ta-C-N phase stabilities [32,33]. Recently analyzed first principles of TaN formation enthalpies by Grumski et al. [34] were preferred in this study over Li et al. [35] and were considered in the model parametrization of Ta-MX.

Hcp $\mathrm{Cr}_{2} \mathrm{~N}$-type carbonitride $\left(\mathrm{M}_{2} \mathrm{X}\right)$ precipitates were identified as relevant "competitors" to MX as Z-phase precursor phases [22]. This especially applies for Z-steels with low $\mathrm{C}$ and high $\mathrm{N}$ content [22]. Moreover, significant $\mathrm{Cr}$-content in $\mathrm{MX}$ has been found [18,22]. Thus, in addition to binary and ternary Ta-C and Ta-C-N stability considerations, $\mathrm{Cr}-$ solubilities in respective carbonitrides needed to be described by appropriate interaction parameters among $\mathrm{Cr}$ and Ta. This enabled us to modulate the Gibbs energies of mixed $\mathrm{MX}(\mathrm{Cr}, \mathrm{Ta})(\mathrm{N}, \mathrm{C})$ and $\mathrm{M}_{2} \mathrm{X}(\mathrm{Cr}, \mathrm{Ta})_{2}(\mathrm{C}, \mathrm{N})$.

The thermodynamic description of Z-phase nitride is defined by the compound energy sublattice formula in analogy to Danielsen and Hald [36], (Cr)(Ta)(N,Va), i.e., replacing $\mathrm{Nb}$ and $\mathrm{V}$ in the second sublattice by Ta. Va denotes empty sites in the interstitial sublattice. The full thermodynamic sublattice description for combined Ta-containing Z-phase and $\mathrm{Cr}(\mathrm{V}, \mathrm{Nb}) \mathrm{N}$ Z-phase, implemented in the "mc_fe" database, $(\mathrm{Cr}, \mathrm{Fe})(\mathrm{Nb}, \mathrm{Mo}, \mathrm{Ta}, \mathrm{V})(\mathrm{N}, \mathrm{Va})$, allows for the replacement of $\mathrm{Nb}, \mathrm{V}$ and Mo in modified Z-phase by Ta. Since the equilibrium stoichiometry of Z-phase was found to be $\mathrm{Cr}_{1.2} \mathrm{Ta}_{0.8} \mathrm{~N}$ [24] rather than $\mathrm{CrTaN}$, the solubility of $\mathrm{Cr}$ was allowed also on the second sublattice. Subsequently, this led to a final sublattice description of $(\mathrm{Cr}, \mathrm{Fe})(\mathrm{Cr}, \mathrm{Nb}, \mathrm{Mo}, \mathrm{Ta}, \mathrm{V})(\mathrm{N}, \mathrm{Va})$. The compound energy of metastable $(\mathrm{Cr})(\mathrm{Cr})(\mathrm{N})$ and the interaction energy between $\mathrm{Cr}$ and $\mathrm{Ta}$ in the second sublattice, $(\mathrm{Cr})(\mathrm{Cr}, \mathrm{Ta})(\mathrm{N})$, was adjusted in order to reproduce the experimental $\mathrm{Z}$-phase stoichiometry. The compound enthalpy is of prime importance for the thermodynamic stability of Z-phase and also for the interfacial energy in precipitation simulations, see, e.g., [37]. In the present thermodynamic description, the enthalpy is approximated to the first-principles result of Urban and Elsässer [38]. The entropic contribution to the molar Gibbs energy of the Z-phase compound $(\mathrm{Cr})(\mathrm{Ta})(\mathrm{N})$ was then adapted to the temperature limit of Z-phase stability, as determined by DSC. Moreover, vacancies were assumed to replace part of the nitrogen, in agreement with previous thermodynamic modelling of $\mathrm{Nb}-\mathrm{V}-\mathrm{Z}$ (Danielsen and Hald [36]). The resulting calculated molar entropy of Z-phase was close to the values of fcc and hcp Cr-Ta nitrides.

The relative phase stabilities of MX and Z-phase obey the criterion of metastable MX [39], which transforms into Z-phase when equilibrium conditions are approached, i.e., after longterm annealing.

Table 2 provides an overview of all the thermodynamic interaction parameters and revised sublattice descriptions added to the "mc_fe.tdb" database. Elements with \% are major constituents. 
Table 2. Revised sublattice descriptions and thermodynamic interaction parameters with Ta (this work).

\begin{tabular}{|c|c|}
\hline BCC_A2 & : Co,Cr,Cu,Fe\%,Mn,Mo,Ni,Si,Ta,V,W : B,C,N,Va\% : \\
\hline \multirow{2}{*}{ Interaction Parameters } & ${ }^{0} G_{\mathrm{Ta}: \mathrm{N}}^{\mathrm{BCC}}{ }^{\mathrm{A} 2}=5 \cdot 10^{4}+{ }^{0} G_{\mathrm{Ta}}^{\mathrm{SER}}+3 \cdot{ }^{0} G_{\mathrm{N}}^{\mathrm{SER}}$ \\
\hline & ${ }^{0} L_{\mathrm{Ta}: \mathrm{N}, \mathrm{Va}}^{\mathrm{BCC}}=125 \cdot 10^{4}-280 \cdot T$ \\
\hline FCC_A1 & : Co,Cr,Cu,Fe\%,Mn,Mo,Ni,Si,Ta,V,W : B,C,N,Va\% : \\
\hline \multirow{4}{*}{ Interaction Parameters } & ${ }^{0} G_{\mathrm{Ta}: \mathrm{C}}^{\mathrm{FCC}}{ }^{\mathrm{A} 1}={ }^{0} G_{\mathrm{Ta}}^{\mathrm{SER}}+3 \cdot{ }^{0} G_{\mathrm{C}}^{\mathrm{SER}}-5 \cdot 10^{4}-60 \cdot T$ \\
\hline & ${ }^{0} G_{\mathrm{Ta}: \mathrm{N}}^{\mathrm{FCC}}{ }^{\mathrm{FC} 1}={ }^{0} G_{\mathrm{Ta}}^{\mathrm{SER}}+3 \cdot{ }^{0} G_{\mathrm{N}}^{\mathrm{SER}}-19 \cdot 10^{4}+95 \cdot T$ \\
\hline & ${ }^{0} L_{\text {Ta:N,Va }}^{\text {BCC_A2 }}=10^{-8}$ \\
\hline & ${ }^{0}{ }_{L_{\mathrm{Cr}, \mathrm{Ta}: \mathrm{N}}^{\mathrm{BCC}}}^{\mathrm{A} 2}=-55 \cdot 10^{3}$ \\
\hline HCP_A3 & : Co,Cr,Cu,Fe\%,Mn,Mo,Ni,Si,Ta,V,W : B,C,N,Va\% : \\
\hline \multirow{5}{*}{ Interaction Parameters } & ${ }^{0} G_{\mathrm{Ta}: \mathrm{C}}^{\mathrm{HCP}}{ }^{\mathrm{A} 3}={ }^{0} G_{\mathrm{Ta}}^{\mathrm{SER}}+0.5 \cdot{ }^{0} G_{\mathrm{C}}^{\mathrm{SER}}-10^{5}+15 \cdot T$ \\
\hline & ${ }^{0} G_{\mathrm{Ta}: \mathrm{N}}^{\mathrm{HCP}}{ }^{\mathrm{A} 3}={ }^{0} G_{\mathrm{Ta}}^{\mathrm{SER}}+0.5 \cdot{ }^{0} G_{\mathrm{N}}^{\mathrm{SER}}-75 \cdot 10^{3}+30 \cdot T$ \\
\hline & ${ }^{0} L_{\mathrm{Cr}, \mathrm{Ta}: \mathrm{Va}}^{\mathrm{HCP}}=-25 \cdot 10^{3}$ \\
\hline & ${ }^{0} L_{\mathrm{Cr}, \mathrm{Ta}: \mathrm{N}}^{\mathrm{HCP}}=-25 \cdot 10^{3}$ \\
\hline & ${ }^{0} L_{\mathrm{Ta}: \mathrm{N}, \mathrm{Va}}^{\mathrm{HCP}}=-25 \cdot 10^{3}$ \\
\hline Z-Phase & $: \mathrm{Cr} \%, \mathrm{Fe}: \mathrm{Cr}, \mathrm{Nb}, \mathrm{Mo}, \mathrm{Ta}, \mathrm{V}: \mathrm{N} \%, \mathrm{Va}:$ \\
\hline \multirow{6}{*}{ Interaction Parameters } & ${ }^{0} G_{\text {Cr:Cr:N }}^{Z-\text { phase }}={ }^{0} G_{\mathrm{Cr}}^{\mathrm{SER}}+{ }^{0} G_{\mathrm{Cr}}^{\mathrm{SER}}+{ }^{0} G_{\mathrm{N}}^{\mathrm{SER}}+15 \cdot 10^{3}$ \\
\hline & ${ }^{0} G_{\mathrm{Cr}: \mathrm{Cr}: \mathrm{Va}}^{\mathrm{Z}-\mathrm{phase}}={ }^{0} \mathrm{G}_{\mathrm{Cr}}^{\mathrm{SER}}+{ }^{0} \mathrm{G}_{\mathrm{Cr}}^{\mathrm{SER}}+2 \cdot 10^{4}$ \\
\hline & ${ }^{0} G_{\text {Cr:Ta:N }}^{Z-\text { phase }}=-225 \cdot 10^{3}+102 \cdot T+{ }^{0} G_{\mathrm{C} r}^{\mathrm{SER}}+{ }^{0} G_{\mathrm{Ta}}^{\mathrm{SER}}+{ }^{0} G_{\mathrm{N}}^{\mathrm{SER}}$ \\
\hline & ${ }^{0} G_{\mathrm{Cr}: \mathrm{Ta}: \mathrm{Va}}^{\mathrm{Z}-\mathrm{phase}}={ }^{0} G_{\mathrm{Cr}}^{\mathrm{SER}}+{ }^{0} G_{\mathrm{Ta}}^{\mathrm{SER}}$ \\
\hline & ${ }^{0} L_{\text {Cr:Ta:N,Va }}^{Z}=-2 \cdot 10^{5}+85 \cdot T$ \\
\hline & ${ }^{0} G_{\text {Cr:Cr,Ta:N }}^{Z-\text { phase }}=-11 \cdot 10^{4}+18 \cdot T$ \\
\hline
\end{tabular}

The code of all new interaction parameters is available herein as supplement part 1.

Proposed diffusion mobilities of Ta in ferrite and austenite (taken from Fridberg [40]) were inserted into "mc_fe.ddb".

The extended MatCalc databases provided us with the opportunity to simulate Tacontaining alloys. Input parameters are needed for the simulations in MatCalc, which are specified in the following.

\section{Input Parameters for Thermokinetic Simulations}

MatCalc employs the classical nucleation theory (CNT) [41] and calculates growth and coarsening of precipitates as a side product of the SFFK (Svoboda-Fischer-FratzlKozeschnik) model [42], which is based on Onsager's extremum principle [43]. SFFK takes into account the energy dissipation from a) diffusion in the matrix, b) diffusion in the precipitates and c) moving interfaces [42]. In addition, interfacial energies are calculated automatically by MatCalc; for the theory, please refer to the generalized broken-bond model (GBB) $[37,44]$.

Before starting simulations of Ta-containing alloys in MatCalc by applying the new databases, input parameters have to be defined as follows.

\subsection{Chemistry}

The chemical composition is indicated in Table 1. 


\subsection{Simulated Precipitate Phases}

Apart from MX, $\mathrm{M}_{2} \mathrm{X}$ and Z-phase, $\mathrm{M}_{23} \mathrm{C}_{6}$ chromium-carbide and the Laves phase $(\mathrm{Fe}, \mathrm{Cr})_{2}(\mathrm{Mo}, \mathrm{W})$ were also chosen as precipitate phases. Despite the fact that the focus of this study was on the kinetics of Z-phase precursors and their transformation to Z-phase, $\mathrm{M}_{23} \mathrm{C}_{6}$ and Laves phase need to be considered for appropriate interpretations of the simulation, since these precipitates contribute to the distribution of relevant elements, such as $\mathrm{Cr}$ and Mo during heat treatment. BN was indirectly taken into account in the simulations. The $\mathrm{N}$ content was reduced from nominal $0.035 \mathrm{wt} . \%$ to $0.031 \mathrm{wt} . \%$, using the result of the equilibrium calculation, which predicted $0.004 \mathrm{wt} . \% \mathrm{~N}$ to be bound in BN. In this way, the impact of less available $\mathrm{N}$ on MX precursors and subsequently on the Z-phase was accounted for.

\subsection{Simulation Modes}

Equilibrium calculations between 500 and $1500{ }^{\circ} \mathrm{C}$ reveal thermodynamically stable phase fractions and require the chemical composition as the only input.

For precipitation kinetic simulations (this work: Z6), we need additional input parameters, including microstructural information and nucleation settings; see Section 4.4 to Section 4.8.

\subsection{Nucleation Sites}

In the context of nucleation sites (see Table 3), the austenitic matrix must be distinguished from the martensitic matrix. In terms of heterogeneous sites for nucleation, dislocations (d) are relevant in austenite. In martensite, grain boundaries (g) and subgrain boundaries (s) are considered in addition. For Z-phase, MX precursor carbonitrides serve as precipitation sites.

Table 3. Z6 nucleation sites for precipitate kinetic simulation.

\begin{tabular}{cccccc}
\hline \multirow{2}{*}{ Nucleation Sites Z6 } & MX & $\mathbf{M}_{\mathbf{2 3}} \mathbf{C}_{\mathbf{6}}$ & Laves & $\mathbf{Z}$ \\
\hline \multirow{2}{*}{ Matrix } & Austenite & $\mathrm{d}$ & - & - & - \\
\cline { 2 - 6 } & Martensite & $\mathrm{d}, \mathrm{s}$ & $\mathrm{s}$ & $\mathrm{g}$ & $\mathrm{MX}_{\mathrm{i}}$ \\
\hline & $\begin{array}{l}\mathrm{g}=\text { Grain Boundaries; } \\
\mathrm{MX} \text { d = Dislocations; s = Subgrain Boundaries; }\end{array}$ & \\
& &
\end{tabular}

\subsection{Z-Phase Transformation Model}

For Z-phase precipitation on MX precursors, a direct particle transformation model with an equivalent interface energy was used, continuing an approach of [45]. The model reflects the nucleation process of a new phase, here Z-phase, occurring within the volume of precursor precipitates, here MX. This mechanism is denoted as inner-particle nucleation. The transformation is only enabled, if the product phase (Z-phase) is thermodynamically more stable than the parent phase (MX); i.e., the stabilities of parent and product phase are continuously compared based on their modelled thermodynamic driving forces. The driving force difference of the two phases serves as effective driving force for nucleation of the product phase. This effective driving force (expressed per volume), $\Delta G_{0, \text { eff }}$, together with an equivalent interface energy, $\gamma_{0 \text {,equ }}$, enters the critical nucleation energy, $G^{*}$, and thus determines the nucleation rate, J, of the product phase (Equations (1) and (2)).

$$
\begin{gathered}
J=N_{0} f_{\mathrm{Z}} \beta^{*} \cdot \exp \left\{-\frac{G^{*}}{k_{\mathrm{B}} T}\right\} \cdot \exp \left\{-\frac{\tau}{t}\right\} \\
G^{*}=\frac{16 \pi}{3} \cdot \frac{\gamma_{0, \mathrm{equ}}^{3}}{\left(\Delta G_{0, \mathrm{eff}}\right)^{2}}
\end{gathered}
$$


The number of available nucleation sites for the product phase, $N_{0}$, corresponds to the number of atoms on the surface of the parent precipitates. Apart from $N_{0}$, Boltzmann constant $k_{\mathrm{B}}$, Zeldovich factor $f_{\mathrm{Z}}$, and atomic attachment rate $\beta^{*}$ are also contained in $J$. Whereas $f_{Z}$ is calculated identically to the case of homogeneous nucleation-related to the probability of a critical nucleus to not dissolve again $-\beta^{*}$ is set to unity because of all elements being already present. The incubation time, $\tau$, is a function of $f_{\mathrm{Z}}$ and $\beta^{*}$. Once a number of $\int J . \mathrm{d} t$ precipitates of the product phase have nucleated (after time $t$ and at a certain temperature $T$ ), an equal number of precursor precipitates is removed from the subsequent simulation increment [46]. For more details on transient nucleation in multicomponent systems, see $[47,48]$. A similar model has recently been proposed for the phase transformation of carbides [49], lacking however an embedding into an advanced thermokinetic framework as offered by MatCalc.

\subsection{Heat Treatment}

Simulative heat treatment setup of Z6 comprised several steps: Z6 was first normalized (N) for 1 hour at $1100^{\circ} \mathrm{C}$. Double-step tempering for $2 \mathrm{~h}$ at $650^{\circ} \mathrm{C}(\mathrm{T} 1)$ and for $2 \mathrm{~h}$ at $750{ }^{\circ} \mathrm{C}$ (T2) was finally followed by ageing (A) for $1000 \mathrm{~h}$ at $700{ }^{\circ} \mathrm{C}$. The thermal history of Z6 is portrayed in Figure 1.

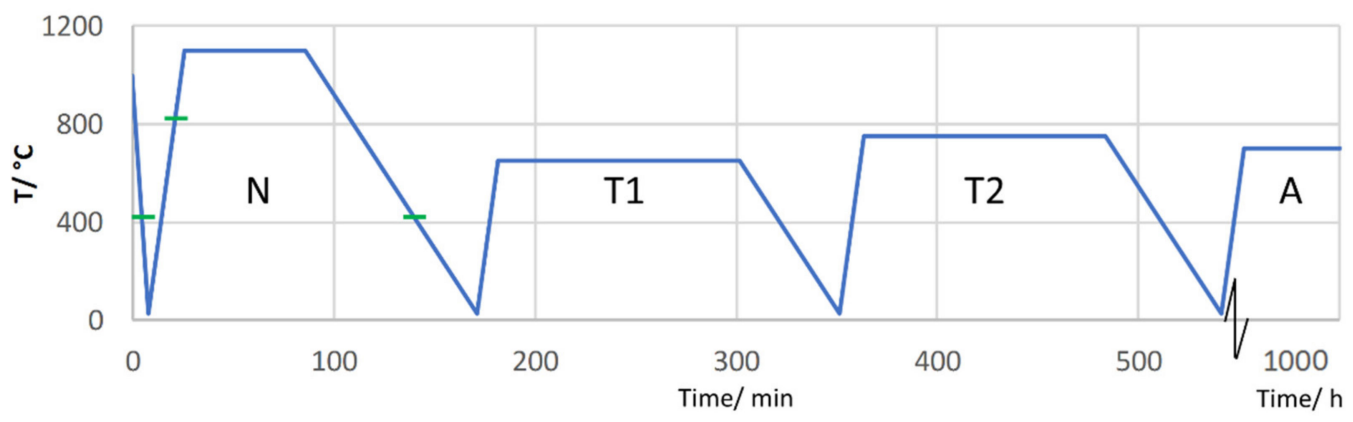

Figure 1. Thermal history of Z6.

When exceeding the re-austenitization temperature of $820^{\circ} \mathrm{C}$ during heating, MatCalc switches the precipitation domain from martensite to austenite. During cooling, $420{ }^{\circ} \mathrm{C}$ was defined as transition temperature from austenite to martensite matrix. Both matrix changes are symbolized in Figure 1 by horizontal green lines before and during $\mathrm{N}$.

\subsection{Microstructural Settings}

Regarding the microstructure of Z6, a prior austenitic grain size (diameter) of $48 \mu \mathrm{m}$ was implemented in accordance with experimental results [29]. The initial subgrain size (diameter) was set at $0.41 \mu \mathrm{m}$ in agreement with TEM measurements-see Section 5.2.

Dislocation densities were varied throughout the simulation. For austenite, a dislocation density of $10^{11} \mathrm{~m}^{-2}$ was adopted from [45]. For martensite, the static recovery part of a state-parameter-based recrystallization model from [50,51] was implemented. The evolution of dislocation density $\rho_{\text {int }}$ in subgrain interiors can subsequently be described by Equation (3):

$$
\dot{\rho}_{\text {int }}=-2 C D_{\mathrm{s}} \frac{G b^{3}}{k_{\mathrm{B}} T}\left(\rho_{\text {int }}^{2}-\rho_{\text {int,eq }}^{2}\right)
$$

where $b$ denotes the Burgers vector, $D_{\mathrm{S}}$ the self-diffusion coefficient (taken from [52]), $G$ the shear modulus and $T$ the temperature. $\rho_{\text {int,eq }}$ is the equilibrium dislocation density. Parameter $C$ controls the speed of static recovery [50].

For the normalizing and tempering, the dislocation density of fresh martensite was distinguished from that of tempered martensite based on TEM analysis. Between those two different levels of dislocation density, a simulation for static recovery was carried 
out, making use of Equation (3). Parameter $C$ was set to $3 \times 10^{-4}$. During ageing, static recovery was modelled in the same way, being supported by our TEM data.

\subsection{Z-Phase Settings}

For Z-phase precipitates and their nucleation linked to MX precursors, the transformation settings turned out to be essential, including an equivalent interface energy $\gamma_{0 \text {,equ }}$ of $0.22 \mathrm{Jm}^{-2}$ and a minimum nucleation radius $(m n r)$ of $5 \AA$. $m n r$ was estimated based on crystallographic unit cell and lattice parameters of Z-phase as stated in [16,53]. For further discussion, please refer to Section 7.5.

Table 4 summarizes all named input parameters for the precipitation kinetic simulation of Z6, in addition to the already given chemical composition (Table 1 ) and nucleation sites (Table 3).

Table 4. Input parameters for MatCalc 6.03 precipitate kinetic simulation of Z6.

\begin{tabular}{|c|c|c|c|c|}
\hline \multicolumn{2}{|c|}{ Input MatCalc } & \multicolumn{2}{|c|}{ Value } & Source \\
\hline \multicolumn{2}{|c|}{ Databases } & \multicolumn{2}{|c|}{ mc_fe_v2.061.tdb and mc_fe_v2.013.ddb } & This work \\
\hline \multirow{3}{*}{$\begin{array}{c}\text { Heat } \\
\text { Treatment }\end{array}$} & Normalizing & \multicolumn{2}{|c|}{$1 \mathrm{~h} @ 1100{ }^{\circ} \mathrm{C}$} & \multirow{3}{*}{ [29] } \\
\hline & Tempering & \multicolumn{2}{|c|}{$2 \mathrm{~h} @ 650{ }^{\circ} \mathrm{C} \& 2 \mathrm{~h} @ 750{ }^{\circ} \mathrm{C}$} & \\
\hline & Ageing & \multicolumn{2}{|c|}{$1000 \mathrm{~h} @ 700$ ㄷ } & \\
\hline \multicolumn{2}{|c|}{ PAGS } & \multicolumn{2}{|c|}{$48 \mu \mathrm{m}$} & [29] \\
\hline \multicolumn{2}{|c|}{ Subgrain Size } & \multicolumn{2}{|c|}{$0.41 \mu \mathrm{m}$} & TEM \\
\hline \multirow{4}{*}{$\begin{array}{l}\text { Dislocation } \\
\text { Density }\end{array}$} & Austenite & \multicolumn{2}{|c|}{$1 \times 10^{11} \mathrm{~m}^{-2}$} & {$[45]$} \\
\hline & $\begin{array}{c}\text { Fresh } \\
\text { Martensite }\end{array}$ & \multicolumn{2}{|l|}{$6.0 \times 10^{14} \mathrm{~m}^{-2}$} & \\
\hline & $\begin{array}{c}\text { Tempered } \\
\text { Martensite }\end{array}$ & $2.6 \times 10^{14} \mathrm{~m}^{-2}$ & \multirow[t]{2}{*}{$\begin{array}{l}\text { Equation (3) } \\
C=3 \times 10^{-4}\end{array}$} & $\begin{array}{c}{[50]} \\
\text { calibrated } \\
\text { by TEM (this work) }\end{array}$ \\
\hline & Ageing & $\begin{array}{l}\text { Start: } 2.6 \times 10^{14} \mathrm{~m}^{-2} \\
\text { End: } 8 \times 10^{13} \mathrm{~m}^{-2}\end{array}$ & & \\
\hline \multicolumn{2}{|c|}{ Martensite Start Temperature } & \multicolumn{2}{|c|}{$420^{\circ} \mathrm{C}$} & [29] \\
\hline \multicolumn{2}{|c|}{ Reaustenitization Temperature } & \multicolumn{2}{|c|}{$820^{\circ} \mathrm{C}$} & [29] \\
\hline \multirow{2}{*}{ Z-Phase } & $\gamma_{0, \text { equ }}$ & \multicolumn{2}{|c|}{$0.22 \mathrm{Jm}^{-2}$} & Fit \\
\hline & $m n r$ & \multicolumn{2}{|c|}{$5 \AA$} & {$[16,53]$} \\
\hline
\end{tabular}

\section{Results of the TEM Measurements}

Figure 2 portrays all investigated sample conditions $(0,1$ and 2$)$ and shows which microstructural features were characterized. $\rho_{\text {int }}$ denotes the internal dislocation density, $D_{\text {sgb }}$ the subgrain size, $D_{\mathrm{i}}$ the precipitate size and $N_{\mathrm{V}}$ the number density.

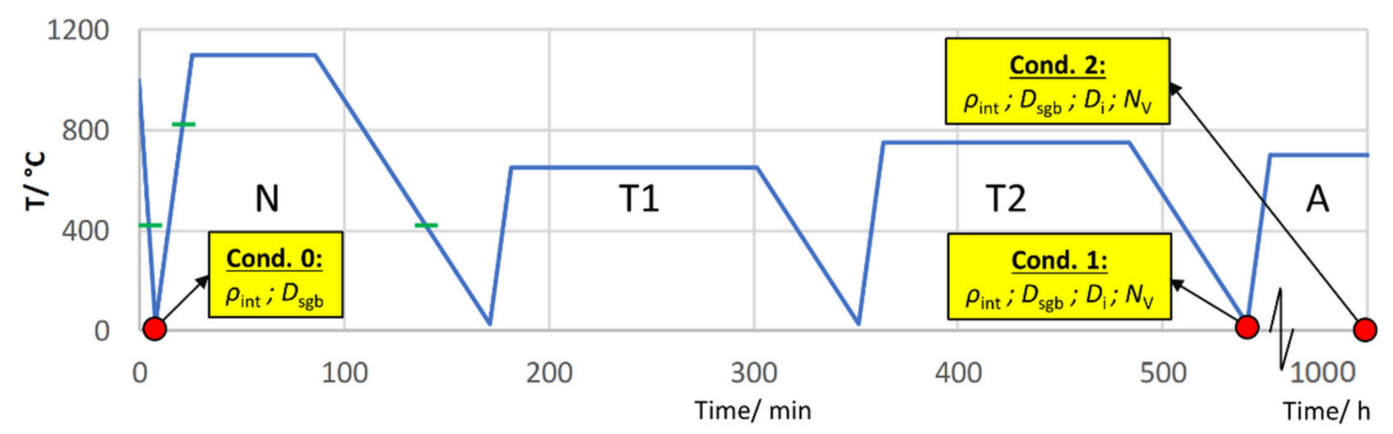

Figure 2. Investigated sample conditions and microstructural features of Z6. 


\subsection{Precipitates}

Figure 3 shows TEM impressions of precipitates in (a) condition $1(\mathrm{~N}+\mathrm{T})$ and $(\mathrm{b})$ condition $2\left(1000 \mathrm{~h}\right.$ aged at $\left.700{ }^{\circ} \mathrm{C}\right)$. The average Cr:Ta ratio is given for MX and Z-phases, which were also identified by SAD. MX/Z-hybrid particles [26] in the as-received state show that the transformation was currently ongoing and not yet completed. After ageing, all $\mathrm{MX}$ and MX/Z-hybrids appeared to be completely replaced by coarsened Z-phase precipitates. Apart from that, some large Laves phase and $\mathrm{M}_{23} \mathrm{C}_{6}$ precipitates close to and above the $\mu \mathrm{m}$ scale, respectively, were detected after ageing.

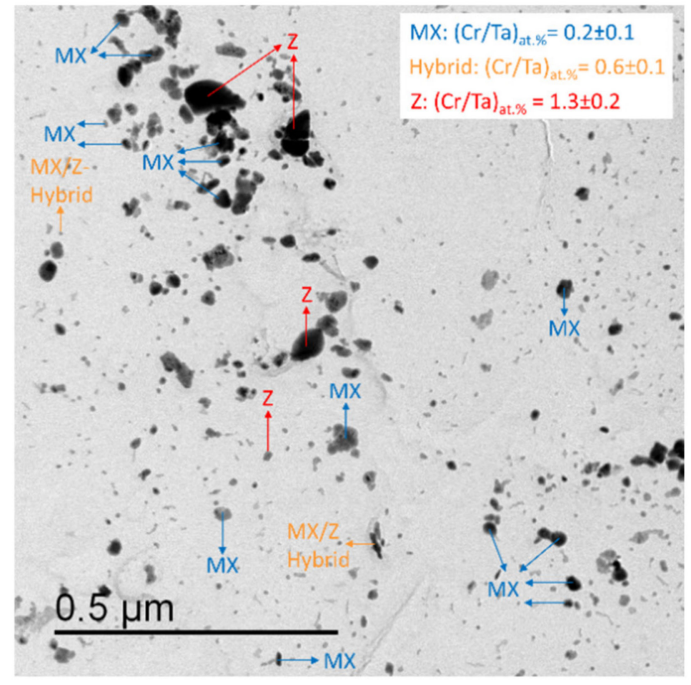

(a)

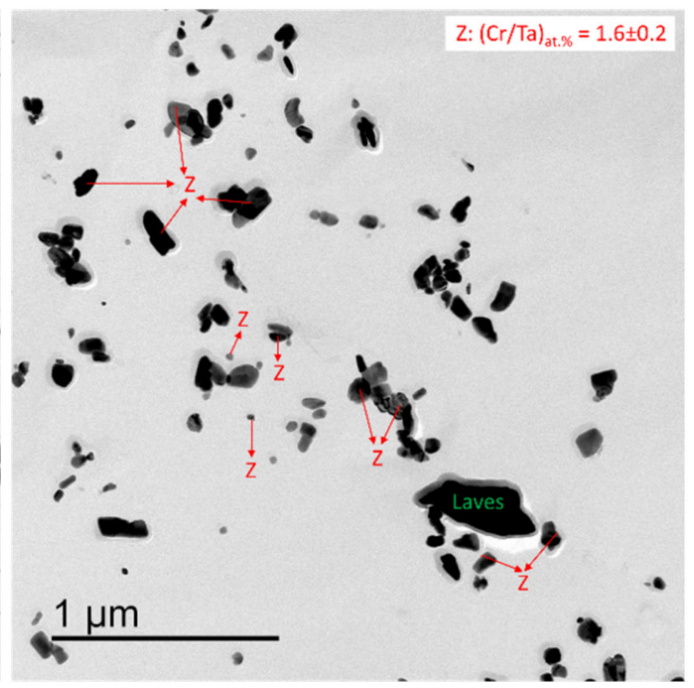

(b)

Figure 3. TEM extraction replicas of Z6 in (a) condition 1 and (b) condition 2.

Table 5 summarizes the observed precipitate sizes $D_{\mathrm{i}}$ and the total number densities $N_{\mathrm{V}}$ in the two conditions obtained from extraction replica, which were investigated by CSM.

Table 5. Precipitate sizes and number densities from Z6 TEM analysis.

\begin{tabular}{|c|c|c|c|c|c|}
\hline Cond. & Prec. & $D_{\mathrm{i}} / \mathrm{nm}$ & $N_{\text {EDX }}$ & $N_{\mathrm{V}} / \mathbf{m}^{-3}$ & $N_{\text {Size }}$ \\
\hline \multirow{3}{*}{1} & MX & $34 \pm 30$ & 64 & \multirow{3}{*}{$3.7 \times 10^{21}$} & \multirow{3}{*}{4246} \\
\hline & $\mathrm{Z}$ & $61 \pm 25$ & 34 & & \\
\hline & Laves & $108 \pm 24$ & 5 & & \\
\hline \multirow{3}{*}{2} & $\mathrm{Z}$ & $79 \pm 38$ & 88 & \multirow{3}{*}{$2 \times 10^{20}$} & \multirow{3}{*}{2434} \\
\hline & Laves & $551 \pm 270$ & 32 & & \\
\hline & $\mathrm{M}_{23} \mathrm{C}_{6}$ & $2728 \pm 954$ & 6 & & \\
\hline
\end{tabular}

It must be mentioned that the number of investigated particles was very low for $\mathrm{M}_{23} \mathrm{C}_{6}$. In contrast, for the determination of MX and Z-phase sizes, around one hundred particles were analyzed and distinguished by EDX ( $\left.N_{\mathrm{EDX}}\right)$. For evaluation of total number densities, several thousand (number $N_{\text {Size }}$ ) were counted, but not individually characterized by EDX. In this context, analysis of the measured size distributions with support of our thermokinetic simulation in Section 6.3.1 and Section 6.3.2 (see Figures 11 and 14) will foster a deeper and statistically more profound insight into how the total number densities can be split into different precipitate populations. 


\subsection{Dislocation Densities and Subgrain Sizes}

Internal dislocation density $\left(\rho_{\text {int }}\right)$ and the subgrain size (diameter $\left.D_{\text {sgb }}\right)$ were determined by TEM.

To give an impression, Figure 4 shows (a) some subgrain boundaries and (b) a high number of internal dislocations in the material in as-received condition $1(\mathrm{~N}+\mathrm{T})$. For comparison, Figure 5 displays the $1000 \mathrm{~h}$ aged condition 2 of (a) subgrains and (b) internal dislocations.

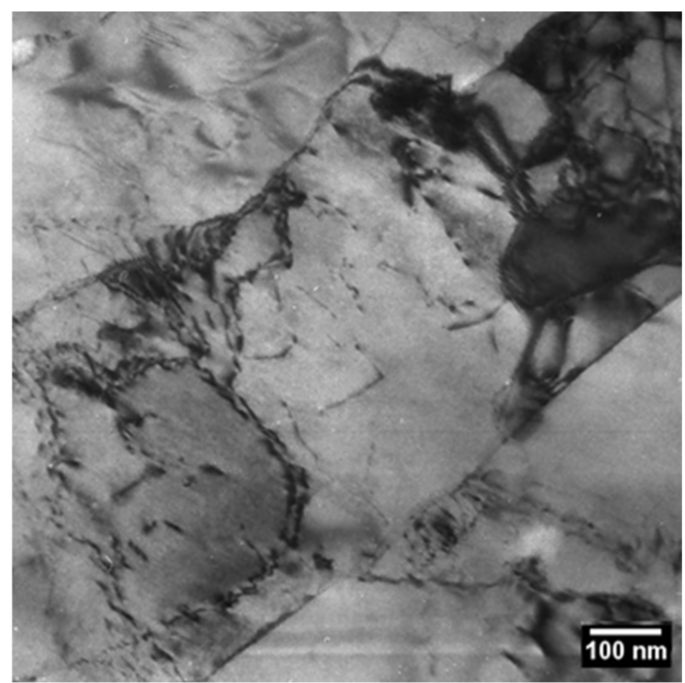

(a)

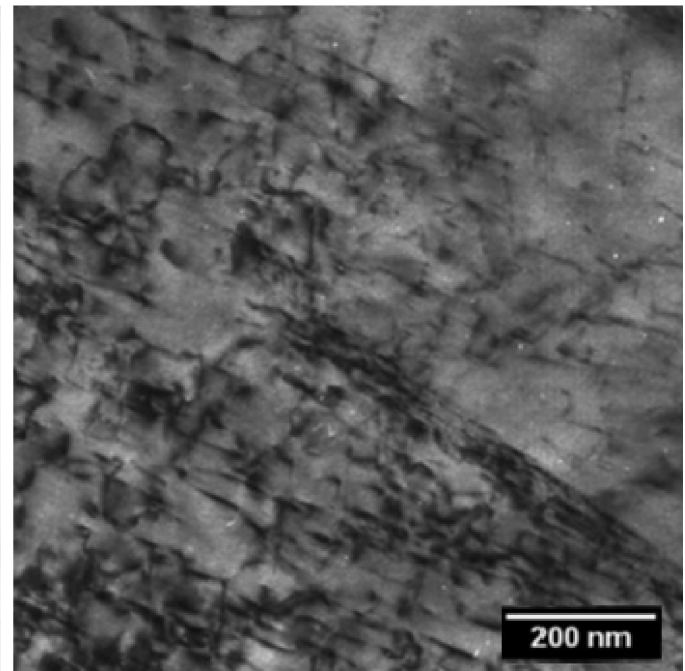

(b)

Figure 4. (a) Subgrain boundaries and (b) internal dislocations in condition $1(\mathrm{~N}+\mathrm{T})$.

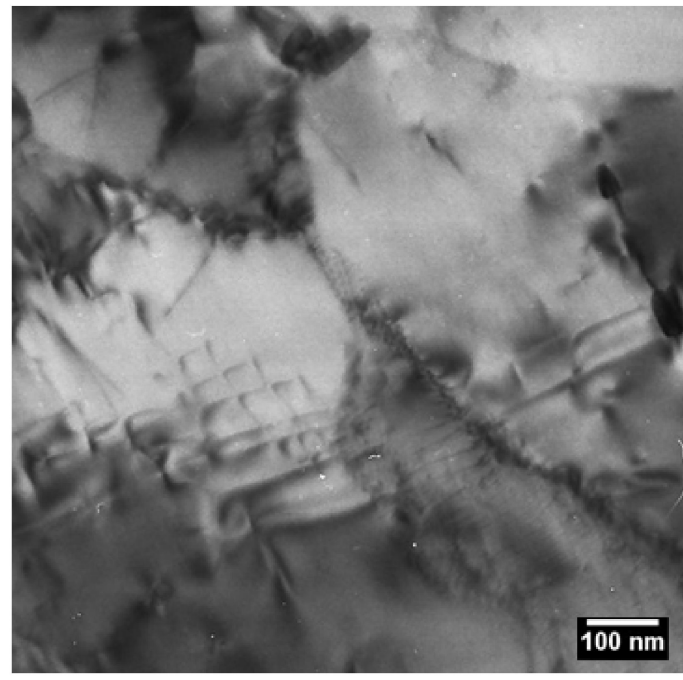

(a)

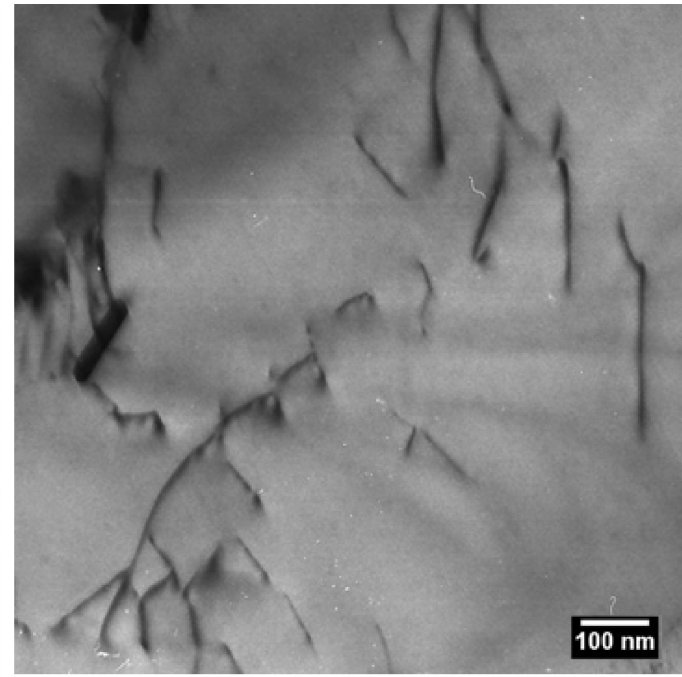

(b)

Figure 5. (a) Subgrain boundaries and (b) internal dislocations in condition $2\left(1000 \mathrm{~h}, 700{ }^{\circ} \mathrm{C}\right)$.

Table 6 provides an overview of all obtained results in conditions 0,1 and 2 . 
Table 6. Dislocation densities and subgrain sizes from Z6 TEM analysis.

\begin{tabular}{cccc}
\hline Cond. & Microstructure & $\rho_{\text {int }}\left[\mathbf{m}^{-2}\right]$ & $D_{\text {sgb }}[\mu \mathrm{m}]$ \\
\hline 0 & Martensite & $6.0 \pm 0.5 \times 10^{14}$ & $0.48 \pm 0.09$ \\
\hline 1 & Tempered Martens. & $2.6 \pm 0.6 \times 10^{14}$ & $0.41 \pm 0.18$ \\
\hline 2 & Aged Temp. Martens. & $7.9 \pm 2.1 \times 10^{13}$ & $0.43 \pm 0.14$ \\
\hline
\end{tabular}

Martensite before the start of normalizing (condition 0) turned out to have the highest dislocation density $\rho_{\text {int }}$ at $6.0 \times 10^{14} \mathrm{~m}^{-2}$. Strong static recovery occurred during tempering, producing tempered martensite with $\rho_{\text {int }}=2.6 \times 10^{14} \mathrm{~m}^{-2}$ (condition 1). Reduction of dislocation density further continued during ageing, reaching $\rho_{\text {int }}=7.9 \times 10^{13} \mathrm{~m}^{-2}$ after $1000 \mathrm{~h}$ of heat input at $700{ }^{\circ} \mathrm{C}$ (condition 2).

$D_{\text {sgb }}$ turned out to be relatively similar before normalizing, in the as-received state $(\mathrm{N}+\mathrm{T})$ and in the aged condition $\left(1000 \mathrm{~h} @ 700{ }^{\circ} \mathrm{C}\right)$, yielding values of $0.48,0.41$ and $0.43 \mu \mathrm{m}$.

\section{Results of MatCalc Simulations}

This chapter presents simulation results (data) from MatCalc which are also pro-vided as supplement part 2 of this work.

\subsection{Equilibrium ZULC and Z6}

Equilibrium calculations of ZULC and Z6 show that between $550{ }^{\circ} \mathrm{C}$ and $700{ }^{\circ} \mathrm{C}$ (see Table 7; Figures 6 and 7), the Laves phase had the highest computed molar phase fraction at 1.2 to $2.5 \%$, followed by Z-phase at approximately $0.4 \% . \mathrm{M}_{23} \mathrm{C}_{6}$ is predicted to exist in ZULC with a $0.1 \%$ phase fraction. In Z6, more $\mathrm{M}_{23} \mathrm{C}_{6}$ is anticipated with 0.2 to $0.4 \%$ due to a higher $C$ content (0.009 to $0.017 \mathrm{wt} . \%)$. Traces of fcc MX $(0.02 \%)$ become stable for Z6 in a range between $595{ }^{\circ} \mathrm{C}$ and $800{ }^{\circ} \mathrm{C}$. Underneath the forming temperature of MX, 0.02 to $0.03 \%$ hcp $\mathrm{Cr}_{2} \mathrm{~N}$ with negligible content of Ta is predicted in Z6. By contrast, neither MX nor $\mathrm{Cr}_{2} \mathrm{~N}$ occurs in equilibrium of ZULC. The computed theoretical dissolution temperatures of Z-phase at $1065^{\circ} \mathrm{C}\left(\mathrm{ZULC}\right.$, Figure 6) and $1050^{\circ} \mathrm{C}(\mathrm{Z6}$, Figure 7) agree with the exothermal DSC peak of the cooling experiment, assuming an undercooling correction of approximately $50^{\circ} \mathrm{C}$ due to kinetic barriers for Z-phase precipitation. In Z6, the lower Z-phase dissolution temperature compared to ZULC is related to stable secondary MX particles appearing between 1040 and $1070{ }^{\circ} \mathrm{C}$. According to MatCalc, BN forms in both alloys with a phase fraction of 0.03 to $0.04 \%$ (more in ZULC due to the higher content of B).

Table 7. Calculated equilibrium phase fraction in mol.\% for ZULC and Z6.

\begin{tabular}{|c|c|c|c|c|c|}
\hline \multirow{2}{*}{ Material } & \multirow{2}{*}{ Precipitate } & $550{ }^{\circ} \mathrm{C}$ & $600{ }^{\circ} \mathrm{C}$ & $650{ }^{\circ} \mathrm{C}$ & $700{ }^{\circ} \mathrm{C}$ \\
\hline & & [mol.\%] & [mol.\%] & [mol.\%] & [mol.\%] \\
\hline \multirow{4}{*}{ ZULC } & Laves & 2.54 & 2.43 & 2.26 & 1.99 \\
\hline & Z-phase & 0.41 & 0.41 & 0.41 & 0.41 \\
\hline & $\mathrm{M}_{23} \mathrm{C}_{6}$ & 0.12 & 0.11 & 0.11 & 0.11 \\
\hline & $\mathrm{BN}$ & 0.04 & 0.04 & 0.04 & 0.04 \\
\hline \multirow{6}{*}{ Z6 } & Laves & 2.36 & 2.10 & 1.71 & 1.16 \\
\hline & Z-phase & 0.42 & 0.42 & 0.42 & 0.41 \\
\hline & $\mathrm{M}_{23} \mathrm{C}_{6}$ & $0.20-0.39$ & $0.20-0.39$ & $0.20-0.38$ & $0.20-0.38$ \\
\hline & $\mathrm{MX}(\mathrm{fcc})$ & None & 0.02 & 0.02 & 0.02 \\
\hline & $\mathrm{Cr}_{2} \mathrm{~N}(\mathrm{hcp})$ & 0.02 & None & None & None \\
\hline & $\mathrm{BN}$ & 0.03 & 0.03 & 0.03 & 0.03 \\
\hline
\end{tabular}




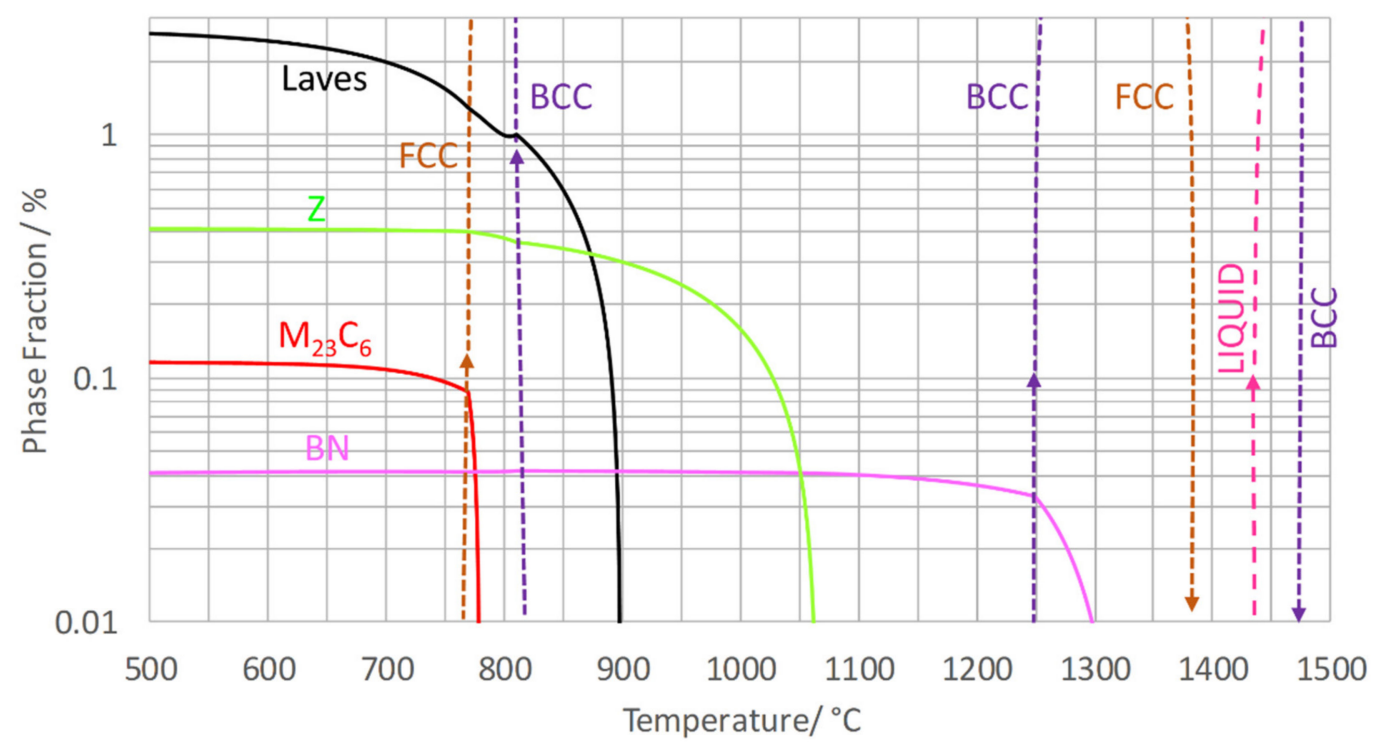

Figure 6. Calculated molar equilibrium phase fractions in ZULC.

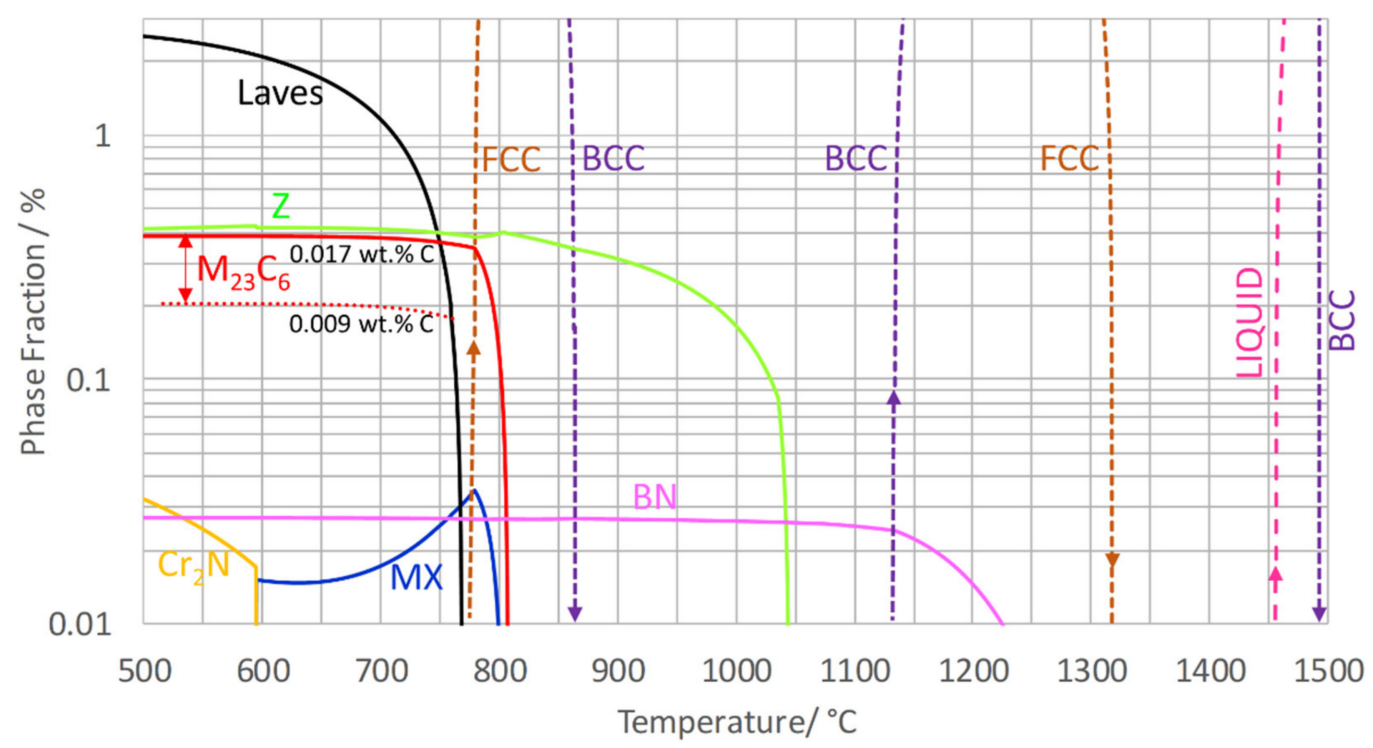

Figure 7. Calculated molar equilibrium phase fractions in Z6.

\subsection{Simulation of Dislocation Evolution}

Before starting to simulate the precipitation kinetics of $\mathrm{Z6}$, the evolution of dislocation density in martensite needs to be carefully modelled and implemented in MatCalc. This concerns the stages of tempering and ageing. Here, we present the results of the previously introduced dislocation evolution model (Equation (3)), linking the obtained TEM data points from Table 6.

During tempering, a simulation of static recovery was conducted using Equation (3). It turns out that the fastest recovery took place during the second tempering step at $750{ }^{\circ} \mathrm{C}$ (T2), whereas dislocation density remained almost unchanged during the first tempering step at $650{ }^{\circ} \mathrm{C}(\mathrm{T} 1)$. In Figure 8 , the underlying TEM start value of $6 \times 10^{14} \mathrm{~m}^{-2}$ and TEM end value of $2.6 \times 10^{14} \mathrm{~m}^{-2}$ are marked by points, the recovery simulation is a full line and the implemented data in MatCalc (additional to the TEM start and end values) are outlined in triangles. 


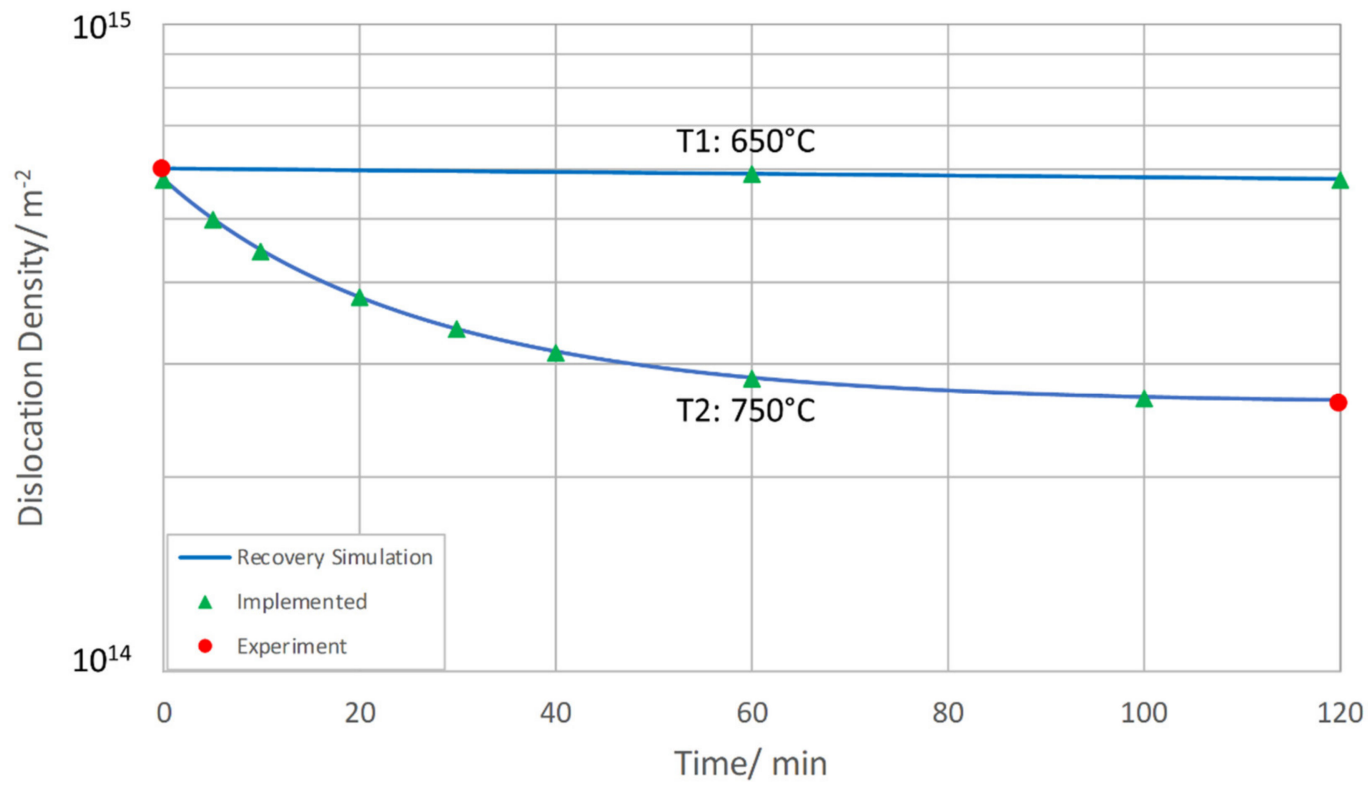

Figure 8. Simulated static recovery during tempering at $650{ }^{\circ} \mathrm{C}(\mathrm{T} 1)$ and $750{ }^{\circ} \mathrm{C}(\mathrm{T} 2)$.

During ageing, static recovery was simulated in the same way, and was incorporated stepwise into MatCalc and calibrated again by our TEM data in as-received condition $(\mathrm{N}+\mathrm{T})$ as well as after $1000 \mathrm{~h}$ of ageing at $700{ }^{\circ} \mathrm{C}$ (see Figure 9).

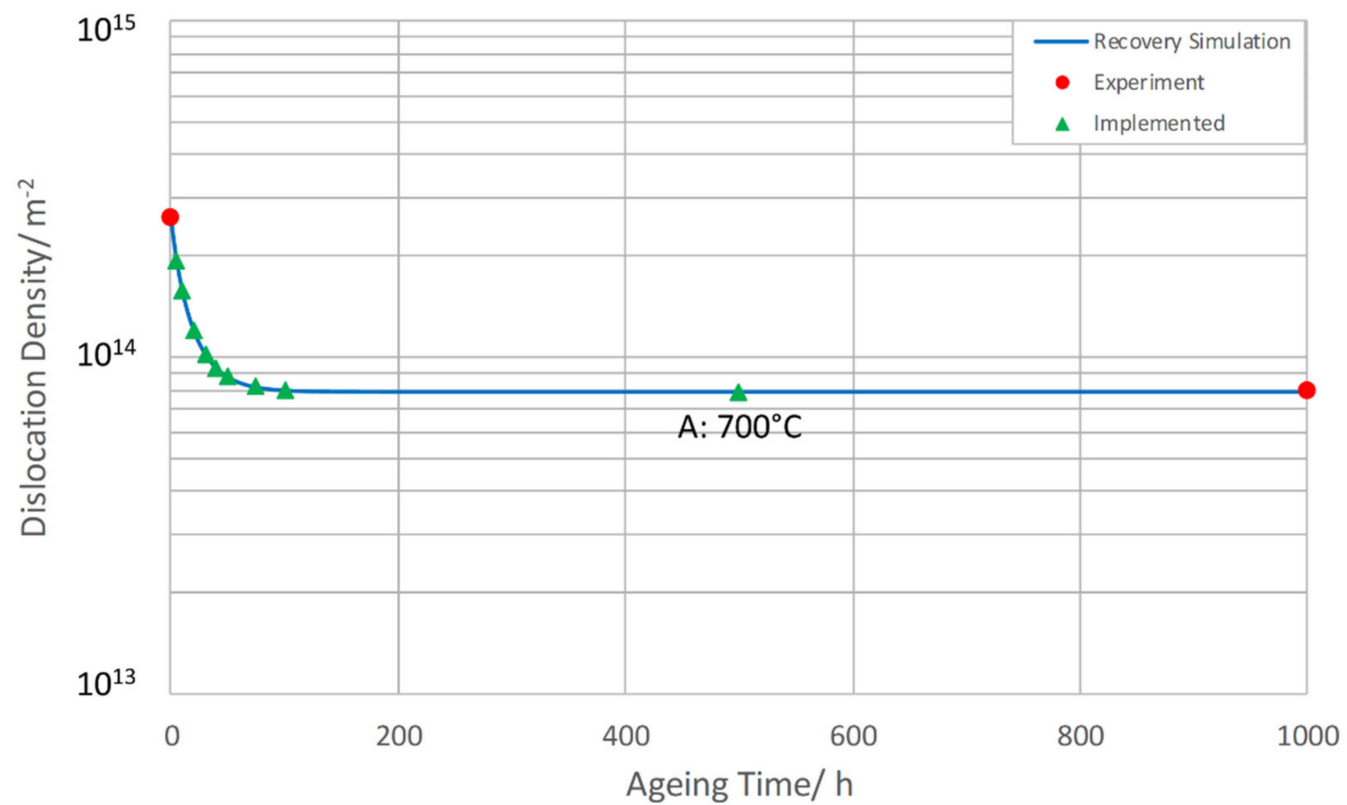

Figure 9. Simulated static recovery of dislocation density during ageing.

\subsection{Precipitate Kinetic Simulation}

This section discusses the results of Z6 precipitation kinetic simulations and compares them to measured TEM data with respect to sizes and number densities. For the simulation shown here, a carbon content of 0.009 wt.\% (obtained from combustion analysis) was chosen. In parallel, we also demonstrate and include the effect of a higher C-content (0.017 wt.\% from OEM) on the evolution of number density and phase fraction of $\mathrm{M}_{23} \mathrm{C}_{6}$. 


\subsubsection{Z6, Heat Treatment Up to Condition $1(\mathrm{~N}+\mathrm{T})$}

Figure 10 summarizes the simulated evolution of mean diameters and number densities of all precipitates during normalizing (N), tempering step 1 at $650{ }^{\circ} \mathrm{C}(\mathrm{T} 1)$ and tempering step 2 at $700{ }^{\circ} \mathrm{C}$ (T2). In condition 1, the TEM data from this work (from Table 5 in Section 5.1) are included.
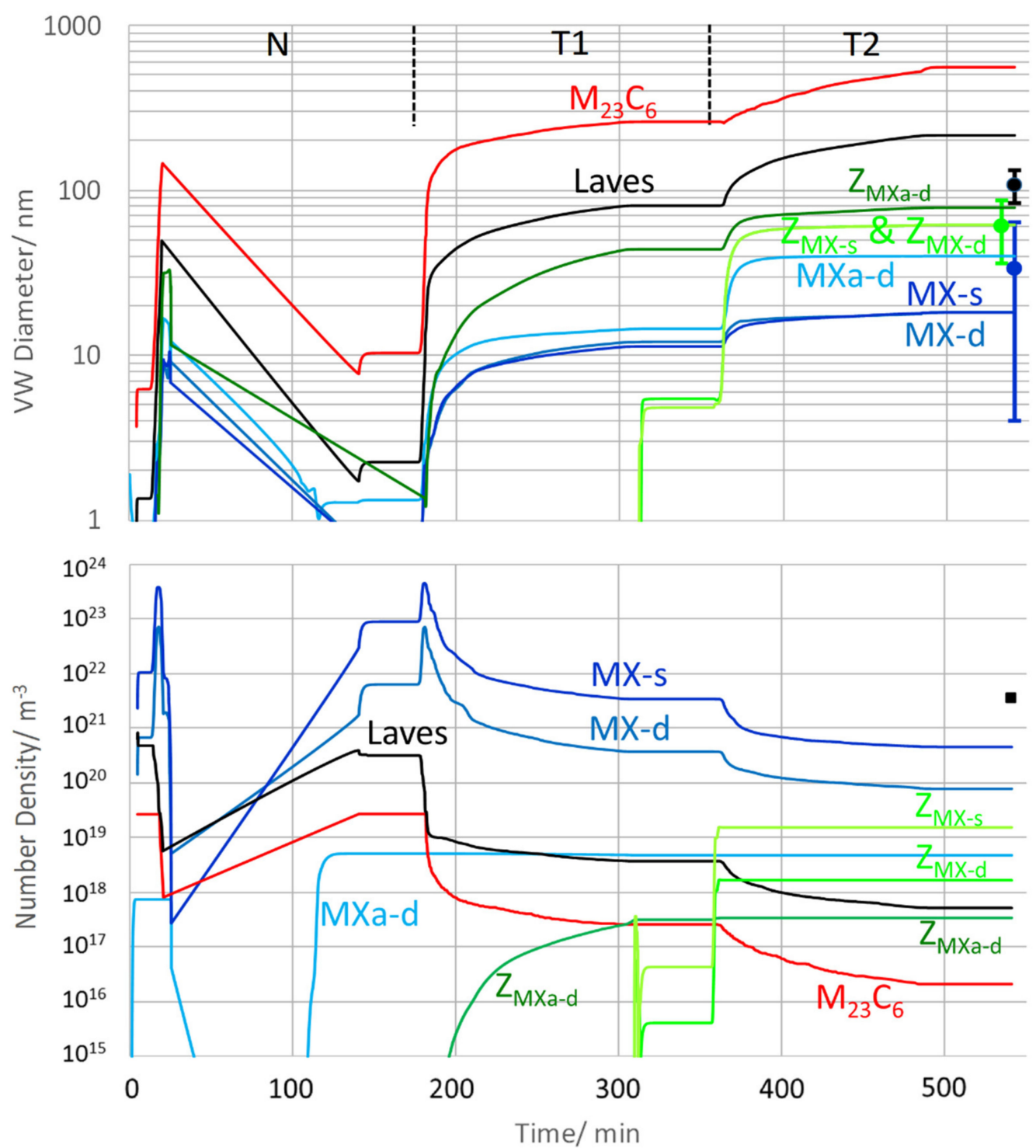

Figure 10. Simulated volume-weighted (VW) diameters and number densities during N + T of Z6 vs. TEM data from Table 5.

The nucleation of MX precursors is started during normalizing, whereas transformation into Z-phase first takes place during tempering step T1. MX nucleating at subgrain boundaries ("MX-s") and at dislocations ("MX- $d$ ") in martensite reach diameters of $18 \mathrm{~nm}$ after T2, which is in satisfactory agreement with the TEM results. The modelled MX originating from dislocations in austenite ("MXa- $d$ ") fit well to the measurements with a diameter of $40 \mathrm{~nm}$. Z-phases transforming from the two smaller MX variants (" $Z_{\mathrm{MX}-\mathrm{s}}$ " and " $Z_{\mathrm{MX}-\mathrm{d}}$ ") developed a mean size of $62 \mathrm{~nm}$, showing excellent agreement with our TEM data. The $Z$-phase forming at the bigger MX variant (" $Z_{\text {MXa-d") }}$ ) had a size of $78 \mathrm{~nm}$. The simulated Laves phase diameter of $215 \mathrm{~nm}$ was overestimated compared to the measured value of $108 \mathrm{~nm}$. However, the number of evaluated particles in TEM was very low; it should be noted that the Laves phase documented in [18] for a similar steel was in the 
range of $200 \mathrm{~nm} . \mathrm{M}_{23} \mathrm{C}_{6}$ become very large in the simulation with around $541 \mathrm{~nm}$. Their size has not been experimentally determined in the $\mathrm{N}+\mathrm{T}$ stage.

Number densities of "MX-s" and " $M X-d$ " have their maximum after normalizing, before a continuous reduction occurs during tempering. Both simulation and TEM measurements confirm that after T2, MX remains the most frequent particle type, followed by Z-phase. The overall number density lies between $5 \times 10^{20} \mathrm{~m}^{-3}$ (simulated) and $3.7 \times 10^{21} \mathrm{~m}^{-3}$ (measured). For evaluation of the experimental number density, area densities were combined with diameters and the sample size (approximately $115 \mathrm{~nm}$ ) according to method 3 from [54].

For a deeper insight into the difference of number densities between the simulation and the TEM measurement, it is worth taking a closer look at size distributions. Figure 11 gives us the opportunity to do so in as-received condition $1(\mathrm{~N}+\mathrm{T})$. The black columns represent size classes from the thermokinetic simulation, and the coloured circles mark to which modelled precipitate population they belong. In comparison, the full orangecoloured line is derived from analysis of TEM data with the same method [54]. For a discussion of the size distributions, please refer to Section 7.6.

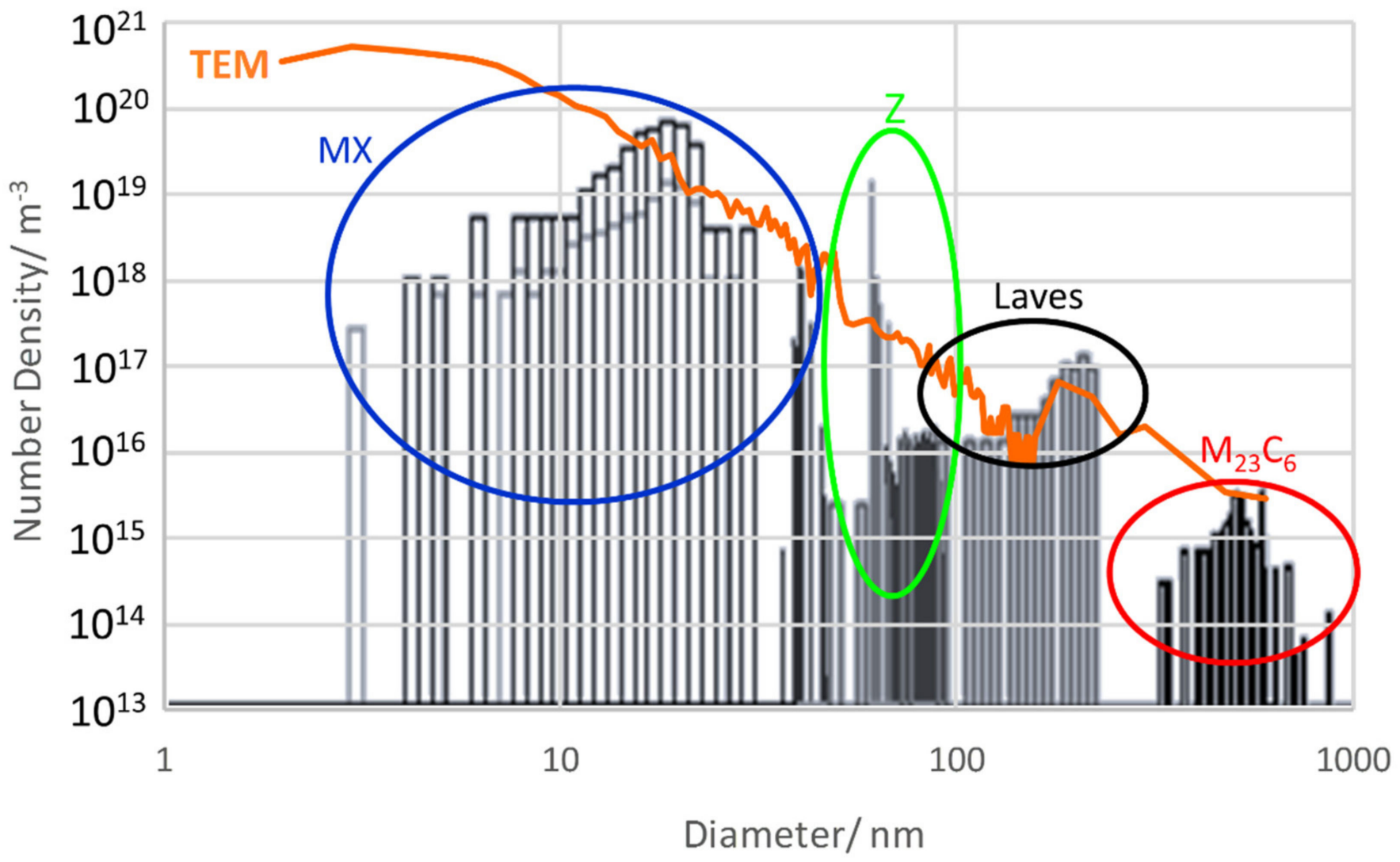

Figure 11. Size distributions of Z6 in as-received condition $1(\mathrm{~N}+\mathrm{T})$; simulated vs. measured.

\subsubsection{Z6, Ageing Up to Condition 2}

Figure 12 summarizes all changes of mean sizes and number densities of precipitates during ageing at $700{ }^{\circ} \mathrm{C}$ for $1000 \mathrm{~h}$. 

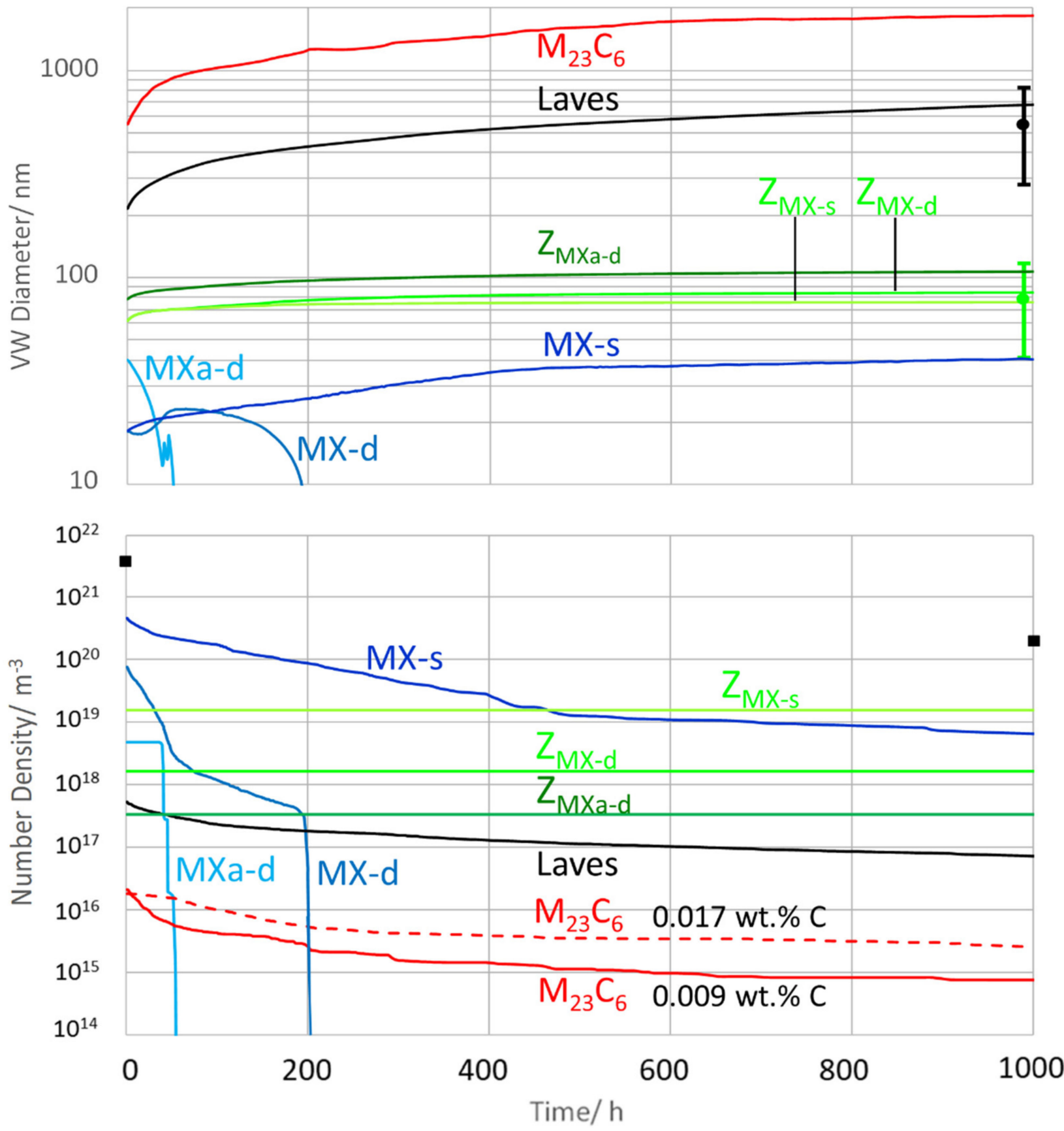

Figure 12. Simulated volume-weighted (VW) diameters and number densities during ageing of Z6 vs. TEM data from Table 5.

During ageing, all ongoing transformations of MX into Z-phases are completed. The two most prominent $Z$-phases " $Z_{\mathrm{MX}-\mathrm{s}}$ " and " $Z_{\mathrm{MX}-\mathrm{d}}$ " coarsened to sizes of 76 and $84 \mathrm{~nm}$, which is in excellent agreement with the TEM measurements. " $Z_{M X a-d}$ " reached $107 \mathrm{~nm}$ and covered the upper end of the measured TEM scatter band. "MXa- $d$ " and "MX- $d$ " disappeared after 60 and 80 hours, respectively, and were fully replaced by the corresponding Z-phases. Only tiny quantities of " $M X-s$ " remain stable without transition into Z-phase (around 0.016\% phase fraction; see Figure 13), reaching a size of $40 \mathrm{~nm}$. Laves phase coarsens to $682 \mathrm{~nm}$ and $\mathrm{M}_{23} \mathrm{C}_{6}$ to $1835 \mathrm{~nm}$. Laves phase was in good line with evaluated TEM data, and $\mathrm{M}_{23} \mathrm{C}_{6}$ proved to be in a reasonable range, since the most observed grain boundary carbides in the aged condition were in the range of 1 to $3 \mu \mathrm{m}$. 


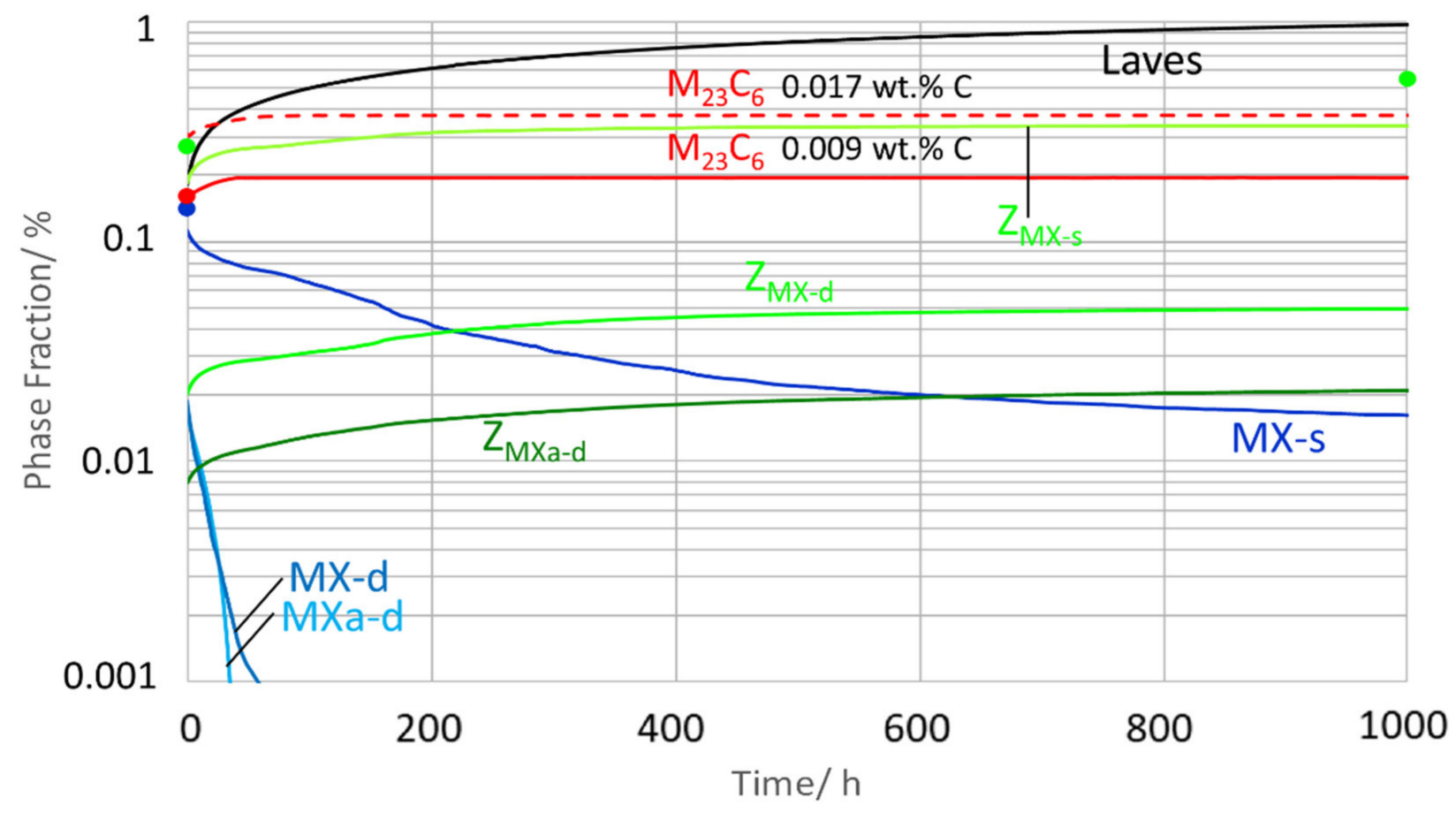

Figure 13. Simulated phase fractions during ageing of $\mathrm{Z6}$ at $700{ }^{\circ} \mathrm{C}$ (condition 1 up to condition 2).

In terms of number density, " $Z_{\mathrm{MX}-\mathrm{s}}$ " maintained the highest value after $1000 \mathrm{~h}$ of ageing at $700{ }^{\circ} \mathrm{C}$ at around $2 \times 10^{19} \mathrm{~m}^{-3}$. "MX-s" and " $\mathrm{Z}_{\mathrm{MX}-\mathrm{d}}$ " followed at approximately $7 \times 10^{18} \mathrm{~m}^{-3}$ and $2 \times 10^{18} \mathrm{~m}^{-3}$. It was confirmed by TEM that the overall number density during ageing at $700{ }^{\circ} \mathrm{C}$ strongly decreased and that Z-phase became the most frequent particle type. In addition to the simulated $\mathrm{M}_{23} \mathrm{C}_{6}$ result with $0.009 \mathrm{wt} . \% \mathrm{C}$, the diagram also includes the $\mathrm{M}_{23} \mathrm{C}_{6}$ result with $0.017 \mathrm{wt} . \% \mathrm{C}$. Again, we note a discrepancy between simulation $\left(3 \times 10^{19} \mathrm{~m}^{-3}\right)$ and TEM data $\left(2 \times 10^{20} \mathrm{~m}^{-3}\right)$ of the overall number density.

Figure 13 displays the evolution of the molar phase fractions during ageing.

Laves phase reached the highest molar phase fraction with about $0.97 \%$ in condition 2 . Simulated Z-phase " $Z_{\mathrm{MX} \text {-s }}$ " evolved from $0.19 \%$ in condition 1 to $0.34 \%$ in condition 2 . In

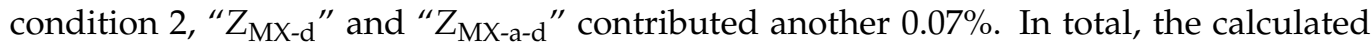
fraction of all Z-phases increased from $0.21 \%$ in condition 1 to $0.41 \%$ in condition 2 . This result is in good agreement with the evaluation of our TEM data according to method 3 in [54], yielding $0.27 \%$ in condition 1 and $0.55 \%$ in condition 2 . The simulated MX phase fraction decreased from $0.12 \%$ in condition 1 (which fits well with a measured quantity of $0.14 \%$ ) to $0.02 \%$ in condition 2. Simulated $\mathrm{M}_{23} \mathrm{C}_{6}$ phase fraction in condition 1 was 0.17 to $0.31 \%$ and in condition 2 lay between 0.20 and $0.34 \%$ (for 0.009 for $0.017 \mathrm{wt} . \% \mathrm{C}$ ). This fits well with the measured quantity of $0.16 \%$ in condition 1 . (Due to the large diameter of $\mathrm{M}_{23} \mathrm{C}_{6}$ in condition 2, statistics for a systematic evaluation of the number density by TEM were not sufficient.)

Once more, we aim to clarify the origin of the difference between simulated and measured number densities (orange line) from investigating size distributions in condition 2; see Figure 14. The diagram shows a better agreement for $\mathrm{M}_{23} \mathrm{C}_{6}$, when selecting $0.017 \mathrm{wt} . \% \mathrm{C}$ for simulation instead of $0.009 \mathrm{wt} . \% \mathrm{C}$. 


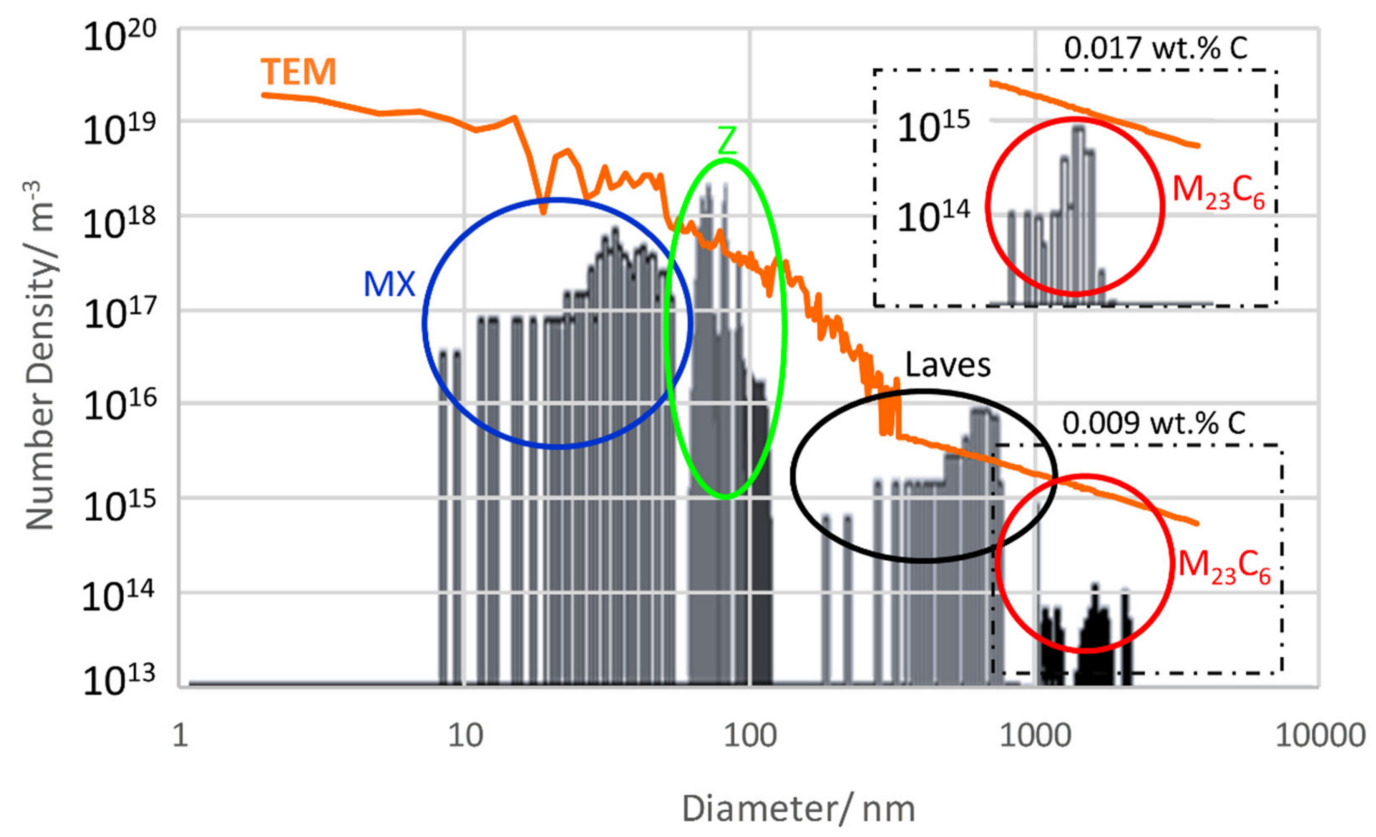

Figure 14. Size distributions of $\mathrm{Z} 6$ in aged condition $2\left(700^{\circ} \mathrm{C} / 1000 \mathrm{~h}\right)$; simulated vs. measured.

\section{Discussion}

\subsection{Z-Phase Precursors MX}

$\mathrm{S}, \mathrm{Ti}, \mathrm{V}, \mathrm{Cr}, \mathrm{Fe}, \mathrm{Nb}$, Mo, Ta and $\mathrm{W}$ were considered within the TEM-EDX measurements; however, the standard deviation of the $\mathrm{S}, \mathrm{Ti}, \mathrm{Nb}$ and Mo signals significantly exceeded the signal dimension itself. Therefore, these elements are excluded from further discussion.

Table 8 compares the simulated chemical composition of MX to our TEM-EDX data. In addition, APT results of Z-steels from the literature are shown, identifying two different chemistries for MX. Type A is almost free of $C$, whereas type B contains a considerable amount of $\mathrm{C}$.

Table 8. MX chemistry of $80 \mathrm{~min} \mathrm{~N}+$ cond. 1 in MatCalc (this work), TEM-EDX (this work) and APT (literature).

\begin{tabular}{|c|c|c|c|c|c|c|c|c|c|c|c|c|}
\hline \multicolumn{6}{|c|}{ MX Simulation Z6 (MatCalc) } & \multicolumn{7}{|c|}{ MX Literature (APT) } \\
\hline \multirow{2}{*}{ Cond. } & \multicolumn{5}{|c|}{ Chem. Comp. [at.\%] } & \multirow{2}{*}{ Cond. } & \multicolumn{4}{|c|}{ Chem. Comp. [at.\%] } & \multirow{2}{*}{ Type } & \multirow{2}{*}{ Ref. } \\
\hline & $\mathrm{Cr}$ & $\mathrm{N}$ & $\mathrm{Ta}$ & $\mathrm{V}$ & $\mathrm{C}$ & & $\mathrm{Cr}$ & $\mathrm{N}$ & $\mathrm{Ta}$ & $\mathrm{C}$ & & \\
\hline \multirow{2}{*}{$80 \min \mathrm{N}$} & \multirow{2}{*}{7.2} & \multirow{2}{*}{26.6} & \multirow{2}{*}{42.2} & \multirow{2}{*}{0.0} & \multirow{2}{*}{23.3} & \multirow{4}{*}{ As-rec. } & 42.6 & 45.9 & 6.6 & 0.4 & $\mathrm{~A}$ & [18] \\
\hline & & & & & & & 35.8 & 48.1 & 9.3 & 0.8 & $\mathrm{~A}$ & [22] \\
\hline \multirow{2}{*}{$\begin{array}{l}\text { As-rec. } \\
(\mathrm{N}+\mathrm{T})\end{array}$} & \multirow{2}{*}{26.7} & \multirow{2}{*}{50.0} & \multirow{2}{*}{22.9} & \multirow{2}{*}{0.3} & \multirow{2}{*}{0.0} & & 17.2 & 13.8 & 27.1 & 32.6 & B & [18] \\
\hline & & & & & & & 18.4 & 29.4 & 27.0 & 13.3 & $\mathrm{~B}$ & [22] \\
\hline \multicolumn{13}{|c|}{ MX Measured (TEM-EDX) } \\
\hline \multirow{2}{*}{ Cond. } & \multicolumn{5}{|c|}{ Chem. Comp. [at.\%] } & & & & & & & \\
\hline & $\mathrm{Cr}$ & $\mathrm{Fe}$ & $\mathrm{Ta}$ & $\mathrm{V}$ & $\mathrm{W}$ & & & & & & & \\
\hline As-rec. & $14 \pm 5$ & $3 \pm 2$ & $75 \pm 9$ & $<1$ & $5 \pm 3$ & & & & & & & \\
\hline
\end{tabular}

When normalized to the metallic part of MX, the MatCalc result $(80 \mathrm{~min} N)$ fits well with the results of TEM-EDX (as-received) and APT of particle type B (as-received). The MatCalc result (as-received) fits well with the APT of particle type A (as-received). It appears there is competition between Ta-rich carbonitrides and Cr-rich nitrides of type MX. 
In order to discuss this situation in more detail, we analyze the evolution of the chemical composition of MX precipitates during normalizing $\mathrm{N}$ and tempering $\mathrm{T} 1 \mathrm{up}$ to the start of Z-phase transformation (see Figure 15).

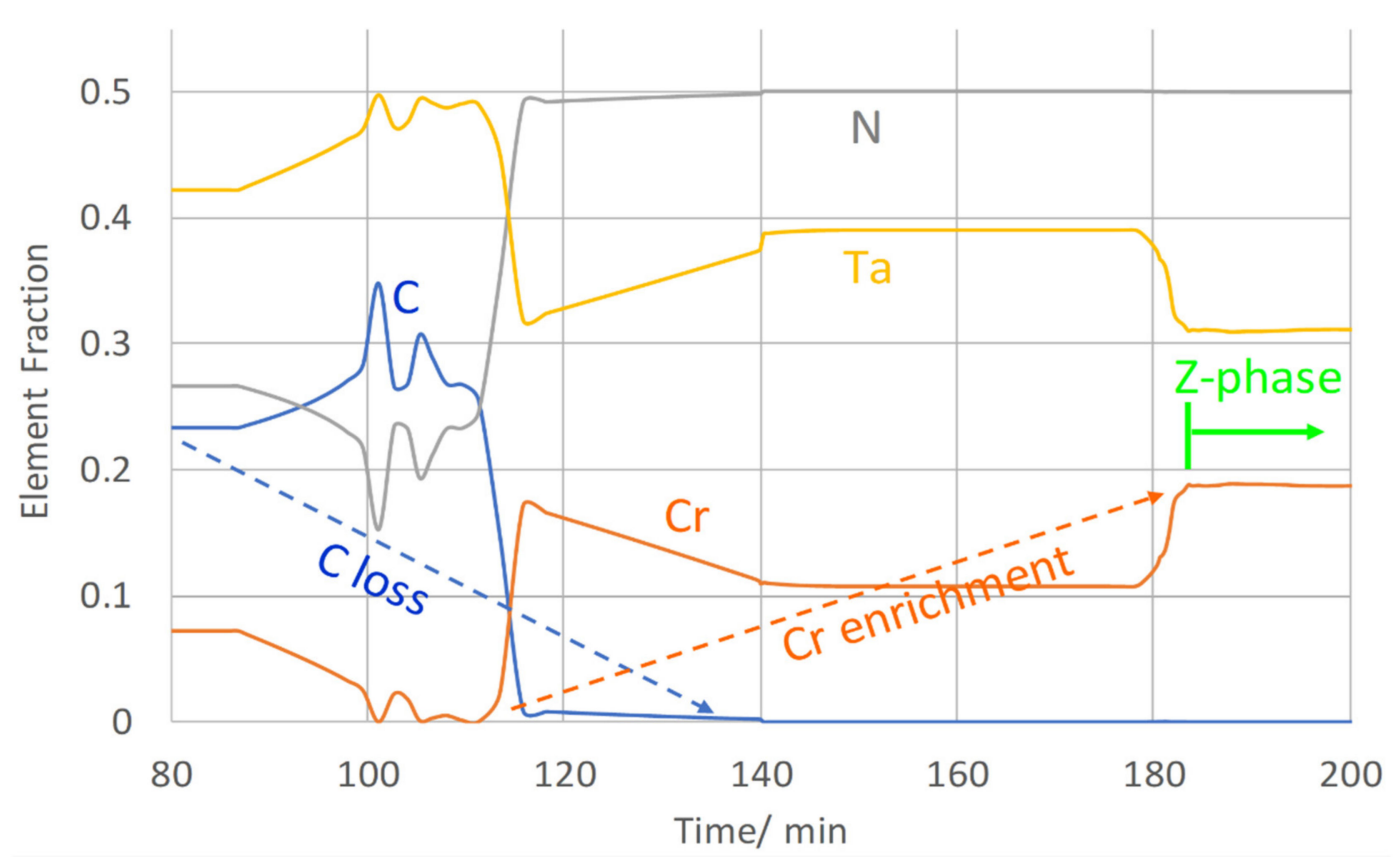

Figure 15. Outtakes of MX chemistry evolution during normalizing and tempering T1.

During normalizing, MX first forms as Ta-rich carbonitride. In the further course of the heat treatment, the precipitates enrich in both $\mathrm{N}$ and $\mathrm{Cr}$. Apparently, this process can be faster or slower for individual particles-see the distinction between particle types A and $\mathrm{B}$ in $[18,22]$. As soon as the Cr-content reaches a critical level, the transformation of MX into the Z-phase starts, as indicated by the green arrow in Figure 15.

\subsection{Z-Phase Precursors $M_{2} X$}

Theoretically, $\mathrm{M}_{2} \mathrm{X}$ precursors may also act as spots for Z-phase (trans-)formation, which is in this case accompanied by Ta intake. However, $\mathrm{M}_{2} \mathrm{X}$ precursors were not selected for Z6 in the thermokinetics simulation since they were not found experimentally. The low quantity of excess $\mathrm{N}$ (corresponding to a ratio of Ta: $\mathrm{N} \approx 1$ ) probably favours nucleation of $\mathrm{MX}$ instead of $\mathrm{M}_{2} X$ [22]. Small quantities of $\mathrm{M}_{2} \mathrm{X}$ do appear in the equilibrium calculations ( 0.02 to $0.03 \%$ phase fraction) but have very little affinity for Ta. In fact, they are $\mathrm{Cr}_{2} \mathrm{~N}$ with only traces of $\mathrm{Ta}(<0.2$ at. $\%)$.

\subsection{Z-Phase Size Evolution}

The simulated evolution of Z-phase size shows excellent agreement with TEM measurements. An important factor to enable a realistic coarsening rate was permitting $\mathrm{Cr}$ to also occupy the second sublattice in the thermodynamic description. This means that $\mathrm{Cr}$ continues to diffuse into the Z-phase until reaching the equilibrium condition of $\mathrm{Cr}_{1.2} \mathrm{Ta}_{0.8} \mathrm{~N}$ [24]. When simplifying Z-phase to a compound $\mathrm{CrTaN}$ and locking out excess $\mathrm{Cr}$, the coarsening is remarkably less pronounced, producing an error of around $25 \%$ with respect to the Z-phase size after $1000 \mathrm{~h}$ of ageing at $700{ }^{\circ} \mathrm{C}$. Moreover, when using the simpler sublattice version, triple the phase fraction of MX remains stable without transformation after $1000 \mathrm{~h}$ of ageing $(0.06 \%)$ when compared to offering a $\mathrm{Cr}_{1.2} \mathrm{Ta}_{0.8} \mathrm{~N}$ sublattice model $(0.02 \%)$. These findings indicate the relevance of appropriate and complete site occupancies for a correct prediction of the MX transformation into the Z-phase. 


\subsection{Chemical Composition of Z-Phase Precipitates}

$\mathrm{S}, \mathrm{Ti}, \mathrm{V}, \mathrm{Cr}, \mathrm{Fe}, \mathrm{Nb}, \mathrm{Mo}$, Ta and $\mathrm{W}$ were considered within the TEM-EDX measurements; however, the standard deviation of the $\mathrm{S}, \mathrm{Ti}, \mathrm{Mo}$ and $\mathrm{Nb}$ signal significantly exceeded the size of the signal. Therefore, these elements are excluded from further discussion.

Simulated chemical compositions of Z-phases fit very well with APT results from the literature and with our TEM-EDX results, as shown by the comparison between MatCalc and experimental data in Table 9.

Table 9. Z-ph. chemistry of cond. $1+2$ in MatCalc (this work), TEM-EDX (this work) and APT (literature).

\begin{tabular}{|c|c|c|c|c|c|c|c|c|c|c|}
\hline \multicolumn{6}{|c|}{ Z-Phase Simulation Z6 (MatCalc) } & \multicolumn{5}{|c|}{ Z-Phase Literature (APT) } \\
\hline \multirow{2}{*}{ Cond. } & \multicolumn{5}{|c|}{ Chem. Comp. [at.\%] } & \multirow{2}{*}{ Cond. } & \multicolumn{3}{|c|}{ Chem. Comp. [at.\%] } & \multirow{2}{*}{ Ref. } \\
\hline & $\mathrm{Cr}$ & $\mathrm{N}$ & Ta & $\mathrm{V}$ & & & $\mathrm{Cr}$ & $\mathrm{N}$ & Тa & \\
\hline As-rec. & 36.9 & 27.3 & 35.7 & 0.1 & & As-rec. & 33.6 & 26.9 & 30.2 & [18] \\
\hline $10^{3} \mathrm{~h} / 700^{\circ} \mathrm{C}$ & 40.7 & 28.7 & 28.4 & 2.2 & & $10^{4} \mathrm{~h} / 650^{\circ} \mathrm{C}$ & 39.8 & 30.2 & 24.1 & [18] \\
\hline \multicolumn{11}{|c|}{ Z-Phase Measured (TEM-EDX) } \\
\hline \multirow{2}{*}{ Cond. } & \multicolumn{5}{|c|}{ Chem. Comp. [at.\%] } & & & & & \\
\hline & $\mathrm{Cr}$ & $\mathrm{Fe}$ & Ta & $\mathrm{V}$ & W & & & & & \\
\hline As-rec. & $51 \pm 7$ & $6 \pm 2$ & $37 \pm 8$ & $2 \pm 1$ & $3 \pm 2$ & & & & & \\
\hline $10^{3} \mathrm{~h} / 700{ }^{\circ} \mathrm{C}$ & $52 \pm 4$ & $5 \pm 2$ & $36 \pm 3$ & $2 \pm 1$ & $3 \pm 1$ & & & & & \\
\hline
\end{tabular}

Although the ageing temperatures were different $\left(700^{\circ} \mathrm{C}\right.$ in our case, $650{ }^{\circ} \mathrm{C}$ in the literature), it is evident that the same equilibrium stoichiometry of $\mathrm{Cr}_{1.2} \mathrm{Ta}_{0.8} \mathrm{~N}$ is reached. Hence, the replacement of the original $(\mathrm{Cr})(\mathrm{Ta})(\mathrm{N})$ sublattice description in our database by a more complex $(\mathrm{Cr})(\mathrm{Cr}, \mathrm{Ta})(\mathrm{N})$ system for the Z-phase turned out to be successful.

Agreement of the simulation results with our TEM-EDX data is also very good. Even though enrichment of Z-phase with $\mathrm{V}$ seems to happen earlier in reality than in simulation, both measurement and MatCalc claim 2 at.\% of $\mathrm{V}$ to enter.

\subsection{Calibration of Transformation Model}

In the thermokinetic simulation setup, the minimum nucleation radius $m n r$ can be understood as the smallest radius of a precipitate that represents the crystal structure of the corresponding phase. For the modified Z-phase, $m n r$ was estimated by investigations of the elementary cell, yielding lattice parameters of $\mathrm{a}=2.86-3 \AA$ and $\mathrm{c}=7.39 \AA[16,53]$. Anything smaller than approximately $5 \AA$ is therefore an atomic cluster rather than an ordered crystallite, thus making our choice for this mnr a reasonable one.

While our Z-phase transformation model exhibits excellent results compared to the experimental data-both in terms of chemical composition and also for the size evolution-, the use of a fitted equivalent interface energy $\gamma_{0 \text {,equ }}$ undoubtedly reveals a weakness of the model. Although the model uses a phenomenological twist to depict a real physical phenomenon, it allows us to bridge metastable MX to stable Z-phase condition. In this context, $\gamma_{0, \text { equ }}$ controls the transformation speed. The higher $\gamma_{0, \text { equ }}$ is chosen, the slower the transition is from MX to Z-phase that will be realized. Despite its unknown exact value, the range of possible energies for Z-phase seems to lie between 0.1 and $0.4 \mathrm{Jm}^{-2}$, as ongoing MatCalc simulations for similar materials involving CrVN Z-phase have shown. Whereas in Z6, $\gamma_{0, \text { equ }}$ was selected as $0.22 \mathrm{Jm}^{-2}$, it had to be chosen higher in, e.g., P91 (with $0.39 \mathrm{Jm}^{-2}$ ) due to slower CrVN Z-phase formation.

\subsection{Overall Number Densities and Size Distributions}

The simulated number densities differ from our TEM data by around one order of magnitude. During ageing, the total number density decreased from around $10^{21} \mathrm{~m}^{-3}$ 
in condition 1 to $10^{20} \mathrm{~m}^{-3}$ in condition 2 according to TEM. By contrast, the simulation predicts a reduction from $10^{20} \mathrm{~m}^{-3}$ in condition 1 to $10^{19} \mathrm{~m}^{-3}$ in condition 2 . Whereas in as-received condition, $\mathrm{MX}$ are most frequent, it is the Z-phase that becomes most prominent after ageing; this is confirmed both by measurement and simulation.

In order to get a more detailed view on the agreement of simulated and measured number densities, we take a closer look at the corresponding size distributions; see Figures 14 and 16.

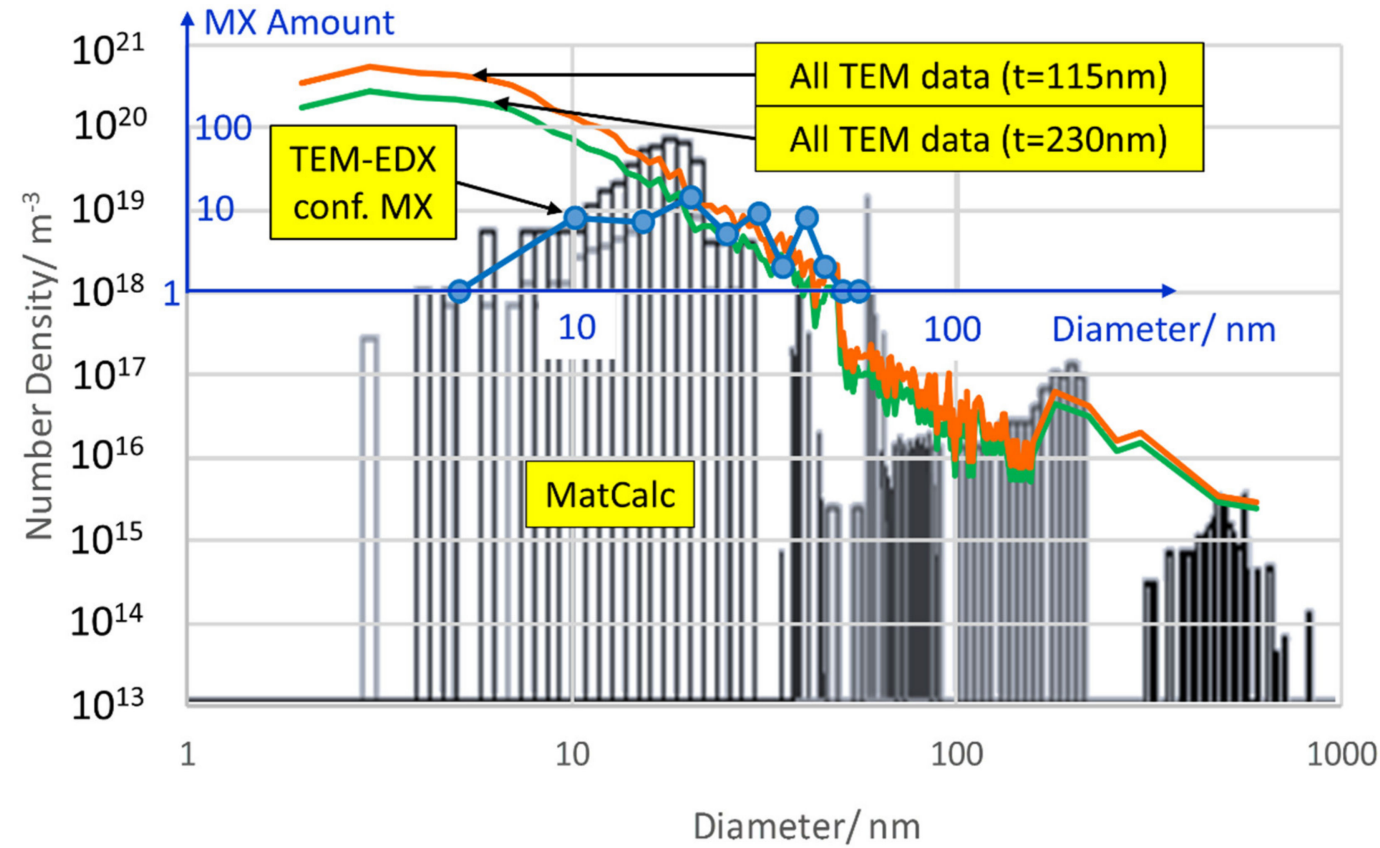

Figure 16. Size distributions of Z6 in condition. $1(\mathrm{~N}+\mathrm{T})$; simulated vs. measured-all data and TEM-EDX confirmed MX sizes within the standard deviation.

Apparently, the agreement is very good for precipitates larger than $10 \mathrm{~nm}$, whereas substantially more small particles were identified in the TEM replica compared to the simulation results. Either the extraction replicas produce artefacts (see e.g., [55]) due to a detection limit for small particles or the simulation underestimates the number of small particles. When excluding precipitates $<10 \mathrm{~nm}$ in condition 1 from the measured data, the number density would decrease remarkably to $8 \times 10^{20} \mathrm{~m}^{-3}$ and move closer to the simulation result of $5 \times 10^{20} \mathrm{~m}^{-3}$ or reduce to $9 \times 10^{19} \mathrm{~m}^{-3}$ as compared to a simulated number of $3 \times 10^{19} \mathrm{~m}^{-3}$ in condition 2 . However, since the detection limit for confirming the nature of particles by EDX is about $10 \mathrm{~nm}$, the question of whether results from TEM or the simulation are closer to reality has to be left open at this point.

One reason for the deviation between simulated and measured number densities is the sample thickness of the TEM samples. For calculating the measured number densities, we assumed a mean thickness of $115 \mathrm{~nm}$. However, TEM sample thickness is not homogeneous and can differ locally. According to our evaluation method, doubling the assumed thickness for the same micrograph leads to about half the number of particles per volume for the smallest precipitates; see green line in Figure 16. For large precipitates (e.g., $>100 \mathrm{~nm}$ ) this effect is less pronounced, and only 20 to $30 \%$ number density reduction can be observed. Thus, the sample thickness can be part of the reason for the deviances.

Another possible source for the deviation is the mean-field approximation made in the simulation approach. Although the experimental size distributions of precipitates often show right-skewed log-normal shapes, the mean-field approximation delivers left-skewed distributions. This issue has been discussed recently by de Nunzio $[56,57]$ and will not be further elaborated here. 


\subsection{Content and Amount of $\mathrm{M}_{23} \mathrm{C}_{6}$}

$\mathrm{C}$ content has been previously determined on a sample taken from the melt liquid by combustion analysis, revealing only $0.009 \mathrm{wt} . \%$ of C [29]. The notable discrepancy to 0.017 wt. \% determined by OEM in this work might be related to segregation effects during solidification, respectively, to an inhomogeneous distribution of $C$. This difference first of all impacts the $\mathrm{M}_{23} \mathrm{C}_{6}$ quantity. Equilibrium test calculations (see chapter 6.1) led to a molar phase fraction of only $0.2 \%$ of $\mathrm{M}_{23} \mathrm{C}_{6}$ with $0.009 \mathrm{wt} . \% \mathrm{C}$, whereas we obtained $0.4 \%$ $\mathrm{M}_{23} \mathrm{C}_{6}$ with 0.017 wt. $\%$ C. Evaluation of size distributions in condition 2 give a hint that the C-content of $0.017 \mathrm{wt} . \%$ detected by OEM seems to be more representative for the zones investigated by TEM.

\subsection{BN Implications}

Equation (4) describes the solubility limit of $\mathrm{BN}$ at $1150{ }^{\circ} \mathrm{C}$ in a $9 \% \mathrm{Cr}$-steel [58].

$$
\log (w t . \% B)=-2.45 \cdot \log (w t . \% N)-6.81
$$

Evaluation shows only 0.019 out of $0.035 \mathrm{wt} . \% \mathrm{~N}$ to be soluble in the matrix of Z6. This speaks for the formation of BN in Z6. However, no BN was detected in similarly alloyed ZULC [18]. A reason for this might be that $\mathrm{Cr}$ decreases the activity of $\mathrm{N}$ [59], with the result that $\mathrm{BN}$ formation is more difficult in $12 \% \mathrm{Cr}$ steels compared to $9 \% \mathrm{Cr}$ steels [18]. Apart from this, the $C$ content-which is argued to raise the activity of $B$ [18] —is much lower in Z6 and in ZULC compared to alloys investigated by [58]. Also in Z6, BN was not found by TEM. The MatCalc equilibrium calculation for Z6 predicts a small molar phase fraction of $0.03 \% \mathrm{BN}$. With a documented size in the $\mu \mathrm{m}$ range [18,22], a number density in reality of approximately $10^{14} \mathrm{~m}^{-3}$ can be estimated. With this number density, it is extremely unlikely that these particles are found in TEM. Furthermore, large BNs are known to be very stable after formation. For this reason, we decided to consider BN by calculating an effective composition of the material, reduced by the amount of $\mathrm{N}$ bound by the BN particles (0.031-0.035 wt.\%). Thus, we correctly took into account the impact of BN on MX formation.

\section{Conclusions}

- Element Ta and its interactions with $\mathrm{Cr}, \mathrm{N}$ and $\mathrm{C}$ - determining the nucleation behaviour of MX precursors and enabling Z-phase to form-have been successfully implemented into the thermodynamic steel database $m c \_f e$.

- The dissolution temperature of Ta-based Z-phase contributed to the parametrization of the thermodynamic model.

- A model based on inner-particle nucleation was applied for the transformation of metastable MX precursors into Z-phase controlled by Cr intake.

- The parameter setup for the thermokinetic calculation involves detailed microstructural input data - in particular dislocation densities-which were gained from TEM measurements and combined with modelling of dislocation evolution.

- The simulation results were validated based on our TEM precipitate results as well as APT data from the literature. Modelled Z-phase size, number density and chemical composition showed excellent agreement to measurements. The simulation greatly contributed to the interpretation of the experimental results from TEM analysis (especially to the size distributions).

- Thermokinetic simulation tools as presented here can assist improved engineering of novel creep-resistant materials to make thermal power plant operation safer, more predictable and more efficient. 


\section{Outlook}

Decoding the correct interaction of $\mathrm{V}$ with $\mathrm{Cr}$, Ta and $\mathrm{N}$ in MX remains a task for the future. To the knowledge of the authors, at the moment, no experimental data are available on phase stabilities and solid solutions in the system Cr-Ta-V-N.

Implementation of the presented microstructural and phase data into a recently published mean-field dislocation creep model [60] is planned.

Supplementary Materials: The following are available online at https:/ /www.mdpi.com/1996-194 4/14/6/1332/s1: Part 1 (Word file): code of the thermodynamic database; Part 2 (Excel file): MatCalc simulation data.

Author Contributions: Conceptualization, F.R. and B.S.; Formal analysis, F.R. and B.S.; Investigation, S.M., M.D. and F.K.; Methodology, E.P.-K. and E.K.; Project administration, O.T. and B.S.; Software, E.P.-K.; Supervision, O.T. and B.S.; Validation, F.R. and B.G.; Visualization, F.R. and B.G.; Writingoriginal draft, F.R.; Writing-review and editing, E.P.-K., E.K. and B.S. All authors have read and agreed to the published version of the manuscript.

Funding: This research has received funding from the European Union's Research Fund for Coal and Steel under grant agreement RFSR-CT-2014-00032, CRESTA2 project. Florian Riedlsperger and Bernhard Sonderegger gratefully acknowledge the support of the Austrian Science Fund FWF in the frame of project "Software Development on Dislocation Creep in Alloys" (P-31374). This research was funded in whole, or in part, by the Austrian Science Fund (FWF) (P-31374). For the purpose of open access, the author has applied a CC BY public copyright license to any author-accepted manuscript version arising from this submission. Financial support by the Austrian Federal Ministry for Digital and Economic Affairs and the National Foundation for Research, Technology and Development is gratefully acknowledged by Erwin Povoden-Karadeniz.

Institutional Review Board Statement: Not applicable.

Informed Consent Statement: Not applicable.

Data Availability Statement: The code of the thermodynamic database is provided as Supplement part 1 (Word). Obtained MatCalc simulation data are contained in Supplement part 2 (Excel).

Acknowledgments: Florian Riedlsperger wants to thank Masoud Rashidi and the Department of Industrial and Materials Science at Chalmers University of Technology for kind communication and for providing samples of ZULC, which were used in DSC. Erwin Povoden-Karadeniz wants to thank Helmut Riedl, TU Wien, Institute of Materials Science and Technology \& CDL_SEC for DSC analysis, data processing and interpretations. Open Access Funding by Graz University of Technology is gratefully acknowledged.

Conflicts of Interest: The authors declare that they have no conflict of interest.

\section{References}

1. Zeiler, G. Martensitic Steels for Rotors in Ultra-Supercritical Power Plants. In Materials for Ultra-Supercritical and Advanced Ultra-Supercritical Power Plants; Di Gianfrancesco, A., Ed.; Woodhead Publishing: Cambridge, UK, 2017; pp. 143-174. ISBN 978-0-08-100552-1.

2. Hald, J. Development status und future possibilities for martensitic creep resistant steels. In Proceedings of the 9th Liége Conference: Materials for Advanced Power Engineering, Liege, Belgium, 27-29 September 2010; pp. 53-64.

3. Raj, B.; Choudhary, B.K. A perspective on creep and fatigue issues in sodium cooled fast reactors. Trans. Indian Inst. Met. 2010, 63, 75-84. [CrossRef]

4. Kalck, C.; Fournier, B.; Barcelo, F.; Forest, L.; Dalle, F.; Giroux, P.-F.; Tournié, I.; Gourgues-Lorenzon, A.-F. High temperature creep properties and microstructural examinations of P92 welds. In Proceedings of the 9th Liége Conference: Materials for Advance Power Engineering, Liege, Belgium, 27-29 September 2010; pp. 424-434.

5. Viswanathan, R.; Gandy, D.; Coleman, K. Advances in Materials Technology for Fossil Power Plants. In Proceedings of the 4th International Conference, Hilton Head Island, SC, USA, 25-28 October 2004; pp. 37-40.

6. Hald, J. Microstructure and long-term creep properties of 9-12\% Cr steels. Int. J. Pres. Ves. Pip. 2008, 85, 30-37. [CrossRef]

7. Abe, F. Grade 91 Heat-Resistant Martensitic Steel. In Coal Power Plant Materials and Life Assessment; Shibli, A., Ed.; Woodhead Publishing: Cambridge, UK, 2014; pp. 3-51. ISBN 978-0-85709-431-5.

8. Maruyama, K.; Sawada, K.; Koike, J. Strengthening Mechanisms of Creep Resistant Tempered Martensitic Steel. ISIJ Int. 2001, 41, 13. [CrossRef] 
9. Pandey, C.; Giri, A.; Mahapatra, M.M. Evolution of phases in P91 steel in various heat treatment conditions and their effect on microstructure stability and mechanical properties. Mater. Sci. Eng. 2016, 664, 58-74. [CrossRef]

10. Cerri, E.; Evangelista, E.; Spigarelli, S.; Bianchi, P. Evolution of microstructure in a modified $9 \mathrm{Cr}-1 \mathrm{Mo}$ steel during short term creep. Mater. Sci. Eng. 1998, 245, 285-292. [CrossRef]

11. Gustafson, Å.; Hättestrand, M. Coarsening of precipitates in an advanced creep resistant $9 \%$ chromium steel-Quantitative microscopy and simulations. Mater. Sci. Eng. 2002, 333, 279-286. [CrossRef]

12. Panait, C.G.; Zielińska-Lipiec, A.; Koziel, T.; Czyrska-Filemonowicz, A.; Gourgues-Lorenzon, A.-F.; Bendick, W. Evolution of dislocation density, size of subgrains and MX-type precipitates in a P91 steel during creep and during thermal ageing at $600{ }^{\circ} \mathrm{C}$ for more than 100,000 h. Mater. Sci. Eng. 2010, 527, 4062-4069. [CrossRef]

13. Panait, C.G.; Bendick, W.; Fuchsmann, A.; Gourgues-Lorenzon, A.-F.; Besson, J. Study of the microstructure of the Grade 91 steel after more than $100,000 \mathrm{~h}$ of creep exposure at $600^{\circ}$ C. Int. J. Pres. Ves. Pip. 2010, 87, 326-335. [CrossRef]

14. Cipolla, L.; Danielsen, H.K.; Venditti, D.; Di Nunzio, P.E.; Hald, J.; Somers, M.A.J. Conversion of MX nitrides to Z-phase in a martensitic 12\% Cr steel. Acta Mater. 2010, 58, 669-679. [CrossRef]

15. Danielsen, H.K. Review of $Z$ phase precipitation in 9-12 wt-\% Cr steels. Mater. Sci. Tech. 2016, 32, 126-137. [CrossRef]

16. Danielsen, H.K.; Hald, J. Tantalum-containing Z-phase in 12\%Cr martensitic steels. Scr. Mater. 2009, 60, 811-813. [CrossRef]

17. Liu, F.; Rashidi, M.; Hald, J.; Reißig, L.; Andrén, H.O. Microstructure of Z-Phase Strengthened Martensitic Steels: Meeting the $650{ }^{\circ} \mathrm{C}$ Challenge. Mater. Sci. Forum 2017, 879, 1147-1152. [CrossRef]

18. Rashidi, M.; Johansson, L.; Andrén, H.-O.; Liu, F. Microstructure and mechanical properties of two Z-phase strengthened $12 \% \mathrm{Cr}$ martensitic steels: The effects of $\mathrm{Cu}$ and C. Mater. Sci. Eng. 2017, 694, 57-65. [CrossRef]

19. Rashidi, M.; Odqvist, J.; Johansson, L.; Hald, J.; Andrén, H.-O.; Liu, F. Experimental and theoretical investigation of precipitate coarsening rate in Z-phase strengthened steels. Materialia 2018, 4, 247-254. [CrossRef]

20. Danielsen, H.K.; Hald, J. On the nucleation and dissolution process of Z-phase $\mathrm{Cr}(\mathrm{V}, \mathrm{Nb}) \mathrm{N}$ in martensitic $12 \%$ Cr steels. Mater. Sci. Eng. 2009, 505, 169-177. [CrossRef]

21. Agamennone, R.; Blum, W.; Gupta, C.; Chakravartty, J.K. Evolution of microstructure and deformation resistance in creep of tempered martensitic 9-12\% Cr-2\% W-5\% Co steels. Acta Mater. 2006, 54, 3003-3014. [CrossRef]

22. Rashidi, M.; Golpayegani, A.; Sheikh, S.; Guo, S.; Andrén, H.-O.; Liu, F. Mechanistic insights into the transformation processes in Z-phase strengthened 12\% Cr steels. Mater. Des. 2018, 158, 237-247. [CrossRef]

23. Vodárek, V.; Filuš, F. On the Role of Z-Phase in Heat Resistant Steels. In Proceedings of the Metal 2011: International Conference on Metallurgy and Materials, Brno, Czech Republic, 8-20 May 2011; pp. 1-6.

24. Ettmayer, P. Die Struktur der Komplexnitride NbCrN und Ta1-xCr1+xN. Chem. Mon. 1971, 102, 858-863. [CrossRef]

25. Liu, F.; Rashidi, M.; Johansson, L.; Hald, J.; Andrén, H.-O. A new 12\% chromium steel strengthened by Z-phase precipitates. Scr. Mater. 2016, 113, 93-96. [CrossRef]

26. Sanhueza, J.P.; Rojas, D.; Prat, O.; García, J.; Meléndrez, M.F.; Suarez, S. Investigation of Ta-MX/Z-Phase and Laves Phase as Precipitation Hardening Particles in a 12 Pct Cr Heat-Resistant Steel. Metall. Mater. Trans. 2018, 49, 2951-2962. [CrossRef]

27. MatCalc. The Materials Calculator. Available online: https://matcalc.at (accessed on 20 December 2020).

28. MatCalc. Open Databases. Available online: https://matcalc.at/index.php/databases/open-databases (accessed on 20 December 2020).

29. Tassa, O.; Matera, S.; Matocha, K.; Kuboň, Z.; Liška, M.; Kurka, V.; Gsellmann, B.; Sonderegger, B.; Iranshahi, F.; Riedlsperger, F.; et al. New Creep Resistant Stable Steel for USC Power Plant; Final Report of EU Project CRESTA2 (RFSR-CT-2014-00032); CSM: Rome, Italy, 2019.

30. Witusiewicz, V.T.; Bondar, A.A.; Hecht, U.; Voblikov, V.M.; Fomichov, O.S.; Petyukh, V.M.; Rex, S. Experimental study and thermodynamic re-assessment of the binary Fe-Ta system. Intermetallics 2011, 19, 1059-1075. [CrossRef]

31. Dupin, N.; Ansara, I. Thermodynamic assessment of the Cr-Ta system. J. Phase Equilib. 1993, 14, 451-456. [CrossRef]

32. Schönberg, N. Ternary metallic phases in the Ta-C-N, Ta-C-O and Ta-N-O systems. Acta Chem. Scand. 1954, 8, 620-623. [CrossRef]

33. Frisk, K. Analysis of the phase diagram and thermochemistry in the Ta-N and the Ta-C-N systems. J. Alloys Compd. 1998, 278, 216-226. [CrossRef]

34. Grumski, M.; Dholabhai, P.P.; Adams, J.B. Ab initio study of the stable phases of 1:1 tantalum nitride. Acta Mater. 2013, 61, 3799-3807. [CrossRef]

35. Li, D.; Tian, F.; Duan, D.; Bao, K.; Chu, B.; Sha, X.; Liu, B.; Cui, T. Mechanical and metallic properties of tantalum nitrides from first-principles calculations. RSC Adv. 2014, 4, 10133-10139. [CrossRef]

36. Danielsen, H.K.; Hald, J. A thermodynamic model of the Z-phase Cr(V, Nb)N. Calphad 2007, 31, 505-514. [CrossRef]

37. Sonderegger, B.; Kozeschnik, E. Size dependence of the interfacial energy in the generalized nearest-neighbor broken-bond approach. Scr. Mater. 2009, 60, 635-638. [CrossRef]

38. Urban, D.F.; Elsässer, C. Atomic defects and dopants in ternary Z-phase transition-metal nitrides $\mathrm{Cr} \mathrm{M} \mathrm{N} \mathrm{with} \mathrm{M}=\mathrm{V}, \mathrm{Nb}, \mathrm{Ta}$ investigated with density functional theory. Phys. Rev. 2017, 96, 104107. [CrossRef]

39. Danielsen, H.K.; Hald, J.; Somers, M.A.J. Atomic resolution imaging of precipitate transformation from cubic TaN to tetragonal CrTaN. Scr. Mater. 2012, 66, 261-264. [CrossRef]

40. Fridberg, J.; Torndahl, L.; Hillert, M. Diffusion in Iron. Jernkontorets Ann. 1969, 153, 263-276.

41. Russell, K.C. Nucleation in solids: The induction and steady state effects. Adv. Colloid Interface Sci. 1980, 13, 205-318. [CrossRef] 
42. Onsager, L. Reciprocal Relations in Irreversible Processes. I. Phys. Rev. 1931, 37, 405-426. [CrossRef]

43. Svoboda, J.; Fischer, F.; Fratzl, P.; Kozeschnik, E. Modelling of kinetics in multi-component multi-phase systems with spherical precipitates I: Theory. Mater. Sci. Eng. 2004, 385, 166-174. [CrossRef]

44. Sonderegger, B.; Kozeschnik, E. Generalized Nearest-Neighbor Broken-Bond Analysis of Randomly Oriented Coherent Interfaces in Multicomponent Fcc and Bcc Structures. Metall. Mater. Trans. 2009, 40, 499-510. [CrossRef]

45. Srinivas Prasad, B.S.; Rajkumar, V.B.; Kumar, H. Numerical simulation of precipitate evolution in ferritic-martensitic power plant steels. Calphad 2012, 36, 1-7. [CrossRef]

46. Kozeschnik, E.; Warczok, P. Treatment of Heterogeneous Nucleation; in MatCalc Documentation. Available online: https: / / www.matcalc.at/wiki/doku.php?id=techpapers:nucleation:het_nucl_sites (accessed on 20 December 2020).

47. Janssens, K.G.F.; Raabe, D.; Kozeschnik, E.; Miodownik, M.A.; Nestler, B. Computational Materials Engineering: An Introduction to Microstructure Evolution; Academic Press: Cambridge, MA, USA, 2010.

48. Radis, R.; Schaffer, M.; Albu, M.; Kothleitner, G.; Pölt, P.; Kozeschnik, E. Multimodal size distributions of $\gamma^{\prime}$ precipitates during continuous cooling of UDIMET $720 \mathrm{Li}$. Acta Mater. 2009, 57, 5739-5747. [CrossRef]

49. Zhou, T.; Babu, R.P.; Hou, Z.; Odqvist, J.; Hedström, P. Precipitation of multiple carbides in martensitic CrMoV steelsExperimental analysis and exploration of alloying strategy through thermodynamic calculations. Materialia 2020, 9, 100630. [CrossRef]

50. Buken, H.; Sherstnev, P.; Kozeschnik, E. A state parameter-based model for static recrystallization interacting with precipitation. Model. Simul. Mater. Sci. Eng. 2016, 24, 35006. [CrossRef]

51. Zamberger, S.; Whitmore, L.; Krisam, S.; Wojcik, T.; Kozeschnik, E. Experimental and computational study of cementite precipitation in tempered martensite. Model. Simul. Mater. Sci. Eng. 2015, 23, 55012. [CrossRef]

52. Nitta, H.; Miura, K.; Iijima, Y. Self-Diffusion in Iron-Based Fe-Mo Alloys. Acta Mater. 2006, 54, 2833-2847. [CrossRef]

53. Danielsen, H.K.; Hald, J.; Grumsen, F.B.; Somers, M.A.J. On the crystal structure of Z-phase Cr(V,Nb)N. Metall. Mater. Trans. 2006, 37, 2633-2640. [CrossRef]

54. Sonderegger, B. Modifications of Stereological Correction Methods for Precipitate Parameters Using Transmission Microscopy. Ultramicroscopy 2006, 106, 941-950. [CrossRef]

55. Kenik, E.A.; Maziasz, P.J. Application of Extraction Replicas and Analytical Electron Microscopy to Precipitate Phase Studies. Report of Oak Ridge National Laboratory 1984. Available online: https:/ /inis.iaea.org/collection/NCLCollectionStore/_Public/ 16/033/16033847.pdf?r=1 (accessed on 8 January 2021).

56. Di Nunzio, P.E. Reinterpretation of the Mean Field Hypothesis in Analytical Models of Ostwald Ripening and Grain Growth. Metall. Mater. Trans. 2019, 50, 2066-2080. [CrossRef]

57. Di Nunzio, P.E. A Discrete Model of Ostwald Ripening Based on Multiple Pairwise Interactions. Philos. Mag. 2018, 98, 1674-1695. [CrossRef]

58. Abe, F. Effect of boron on microstructure and creep strength of advanced ferritic power plant steels. Procedia Eng. 2011, 10, 94-99. [CrossRef]

59. Sakuraya, K.; Okada, H.; Abe, F. BN type inclusions formed in high Cr ferritic heat resistant steel. Energy Mater. 2006, 1, 158-166. [CrossRef]

60. Riedlsperger, F.; Krenmayr, B.; Zuderstorfer, G.; Fercher, B.; Niederl, B.; Schmid, J.; Sonderegger, B. Application of an advanced mean-field dislocation creep model to P91 for calculation of creep curves and time-to-rupture diagrams. Materialia 2020, 12, 100760. [CrossRef] 